OPEN ACCESS

Edited by:

Hua Kun Liu,

University of Wollongong, Australia

Reviewed by:

Manickam Minakshi,

Murdoch University, Australia

Yongliang $\mathrm{Li}$

Shenzhen University, China

*Correspondence:

Wen Liu

wenliu@mail.buct.edu.cn

Xiaoming Sun

sunxm@mail.buct.edu.cn

Specialty section:

This article was submitted to Electrochemical Energy Conversion and Storage,

a section of the journal Frontiers in Energy Research

Received: 07 June 2019 Accepted: 30 September 2019

Published: 30 October 2019

Citation:

Wang H, Cao X, Liu W and Sun X (2019) Research Progress of the Solid State Lithium-Sulfur Batteries.

Front. Energy Res. 7:112. doi: 10.3389/fenrg.2019.00112

\section{Research Progress of the Solid State Lithium-Sulfur Batteries}

\author{
HangChao Wang, Xin Cao, Wen Liu* and Xiaoming Sun* \\ State Key Laboratory of Chemical Resource Engineering, College of Chemistry, Beijing University of Chemical Technology, \\ Beijing, China
}

Lithium-sulfur batteries using lithium as the anode and sulfur as the cathode can achieve a theoretical energy density $\left(2,600\right.$ Wh. $\left.\mathrm{g}^{-1}\right)$ several times higher than that of Li ion batteries based on the chemical conversion reaction of $6 \mathrm{Li}+\mathrm{S}_{8} \leftrightarrow 8 \mathrm{Li}_{2} \mathrm{~S}$. The cost effectiveness, together with the intrinsic high energy density of the Li-S batteries, enables it to be an important option for the next generation energy storage devices. However, lithium-sulfur batteries using the liquid electrolyte would lead to the dissolution and "shuttle effect" of polysulfides, which greatly decrease the cycle life and specific capacity. In order to realize long cycle life of the lithium-sulfur battery, it is crucial to address the uncontrolled diffusion of polysulfides. Replacing the liquid electrolyte with the solid electrolyte, which can address the polysulfide dissolution and diffusion problem, inhibit the growth of lithium dendrites on the anode side, and greatly improve the safety and the cycle stability of lithium-sulfur batteries. In spite of the above merits, the performance and application of solid state Li-S batteries are strongly constrained by their low discharge capacity, poor rate performance and unsatisfied cycle life, which need to be overcome by advances in both the materials and the battery design. In this mini-review, the recent research progress of solid-state lithium-sulfur batteries in several aspects, including the sulfur-cathode design, different types of solid electrolyte and Li-S batteries based on them is described/summarized. New insights and synthesis approaches for the stable lithium anode are also summarized. We particularly emphasize the role of the interface in impeding the battery reaction, as well as the construction of the "solid/solid/solid" three-phase reaction boundary. At last, the prospects and challenges in further advancing the scientific understanding and enabling the battery technology viable are presented to shed light on the upcoming research efforts.

Keywords: all-solid lithium-sulfur battery, anode, solid electrolyte, cathode, interface engineering

\section{INTRODUCTION}

Lithium sulfur batteries use lithium metal as the negative electrode and sulfur elemental or sulfide as the positive electrode (Xu, 2004; Bruce et al., 2011; Chen R. et al., 2016). Among them,the lithium-sulfur battery using the elemental sulfur as the active cathode material has the highest theoretical specific energy density in gravimetric $(2,600 \mathrm{Wh} / \mathrm{kg})$ and capacity density $(2,800 \mathrm{Wh} / \mathrm{L})$, based barely on the mass of active materials. Prototype Li-S pouch cells can already deliver specific energy as high as $600 \mathrm{Wh} / \mathrm{kg}$, which is much higher than that of 
the existing $\mathrm{Li}$ ion batteries $(250 \mathrm{Wh} / \mathrm{kg}$ ) and can meet the target of enabling the electric cars with $>300$ miles driving range. Lithium-sulfur batteries also have the advantages of high output power, abundant sulfur reserves and low cost, and have become one of the commanding heights of energy storage battery technology competition (Xu, 2004; Goodenough and Kim, 2010; Bruce et al., 2011; Chen R. et al., 2015).

Although the performance of lithium-sulfur batteries has been initially verified, the safety and the cycle performance are still standing out as the big barriers in the practical application of lithium-sulfur batteries (Kamyshny et al., 2007; Barchasz et al., 2012; Zhang, 2013). At present, lithium-sulfur batteries using the sulfur cathode usually employ the liquid electrolyte with LiTFSI dissolved in ether solvent, such as 1, 3 dioxane (DOL), dimethoxy-ethane (DME), etc. In general, lithium-sulfur batteries with the liquid electrolyte have achieved success in demonstrating the huge potential of this sulfur battery, but large scale deployment and application are still out of their capability due to the following aspects: (a) During the charging and discharging process of the battery, a long-chain lithium polysulfide intermediate can be formed, which is easily soluble in the liquid electrolyte. The continuous dissolution of the polysulfide increases the viscosity of the electrolyte, meanwhile it also destroys the structure of the cathode. In addition, the precipitation of polysulfides will turn into the insulating $\mathrm{Li}_{2} \mathrm{~S}$ on the surface of the cathode, which would hinder the electronic and ionic migration, and reduce the utilization of sulfur active substances (Xu et al., 2015; Peng et al., 2017). (b) The dissolved long-chain polysulfide diffuses from the cathode to the anode, and the long-chain polysulfide will be reduced to short-chain polysulfide on the anode surface, which then migrates back to the cathode and reconverts into the middle of the chain of lithium polysulfide. The infinite motion of the polysulfide between the cathode and the anode is known as the "shuttle effect" of the polysulfide. During the charging and discharging process, the shuttle effect of the polysulfide causes the low coulombic efficiency and corrosion of the lithium metal anode (Mikhaylik and Akridge, 2004; Bruce et al., 2011). (c) The electrolyte solvent becomes unstable with fresh and porous $\mathrm{Li}$ metal anode after corrosion with polysulfides. On which, the electrolyte is gradually consumed until it is exhausted, and the reaction generates gas which may cause the expansion of the battery,and even explosion (Zhang, 2013; Jozwiuk et al., 2016; Schneider et al., 2017; Hancock et al., 2018). When used under high temperature conditions, the organic solvent is also easily ignited which increases the safety hazard (Chen W. et al., 2018). (d) The uncontrolled lithium deposition in liquid electrolyte leads to the dendrite growth. The uncontrollable dendrite growth leads to the formation of "dead lithium" with low coulombic efficiency, and may even trigger the internal short circuit and catastrophic failure (Cao et al., 2015; Cheng et al., 2017).

In order to overcome the above problems and further improve the performance of lithium-sulfur batteries, researchers have studied a series of countermeasures, including the design of sulfur cathode (Song et al., 2013; Rosenman et al., 2015; Li et al., 2016; Pang et al., 2016; Ye et al., 2018), the protection of lithium anode (Wu et al., 2014, 2015; Cheng X. B. et al.,
2016; Jiaqiang et al., 2017), and the optimization of electrolytes (Arumugam et al., 2014; Zhang S. et al., 2015). In terms of the electrolyte optimization, solid electrolytes including gels, solid polymers, inorganic ceramics and inorganic-organic composite electrolytes are gaining more and more attention (Figure 1). Solid electrolytes can cure many problems caused by liquid electrolytes. In the past few years, a growing body of researches have proved the advantages of solid electrolytes (Liu et al., 2016; Wang S. et al., 2016; Tao et al., 2017). This minireview is intended to summarize the recent progress of $\mathrm{Li}$ sulfur batteries based on the solid electrolytes, including the pros and cons of using gels, solid polymers, inorganic and organicinorganic composites as solid electrolytes; and the progress of solid state Li-sulfur batteries based on either the sulfur cathode or lithium metal anode. The challenges to further advance this battery technology and progress it from laboratory interest to commercial feasibility are also presented, which might shine a light for the development and large-scale applications of the solid lithium battery.

\section{MERITS OF SOLID ELECTROLYTE}

As an important part of lithium-sulfur batteries, the electrolyte plays an important role in the transportation of ions. The liquid electrolyte can realize fast kinetics, but also brings about many concerns on the safety and the cycle life of the battery. The electrolytes currently used are all organic electrolytes of ethers or carbonates. Such electrolytes have poor thermal stability and are prone to leakage and cause safety accidents. Although ionic liquids are highly safe and non-flammable, they are expensive and have certain environmental hazards, and are not suitable for large-scale application in battery systems.

There is an urgent requirement to study the new electrolyte to avoid the "shuttle effect" of the polysulfide $\left(\mathrm{Li}_{2} \mathrm{~S}_{6}, \mathrm{Li}_{2} \mathrm{~S}_{4}\right)$ formed during the charging and discharging process on the premise of ensuring high lithium ion conductivity, thereby improving the utilization of active sulfur species and the cycle life of lithium-sulfur batteries. Solid electrolytes are usually classified into four types: gels, solid polymers, inorganic and inorganicorganic composite electrolytes. Table 1 lists the composition and properties of the different electrolytes. In general, an ideal solid electrolyte should have the properties of higher ion conductivity, better electrical insulation, wider electrochemical window, stable chemical properties, and stable chemical reactivity with the positive and negative electrodes.

\section{Gel Electrolyte}

One of the main reasons hindering the commercialization of all solid-state batteries presently is the poor ionic conductivity of all solid electrolytes at room temperature, which mean the discharge specific capacity of all solid-state batteries is far from the requirement of practical application. In order to solve the problem of poor ionic conductivity of the solid electrolyte at room temperature, the gel electrolyte with a certain amount of liquid electrolyte was developed. The lithium ion transport of the gel electrolyte is basically the same as that of the liquid electrolyte. At the same time, due to the presence of the electrolyte, the 


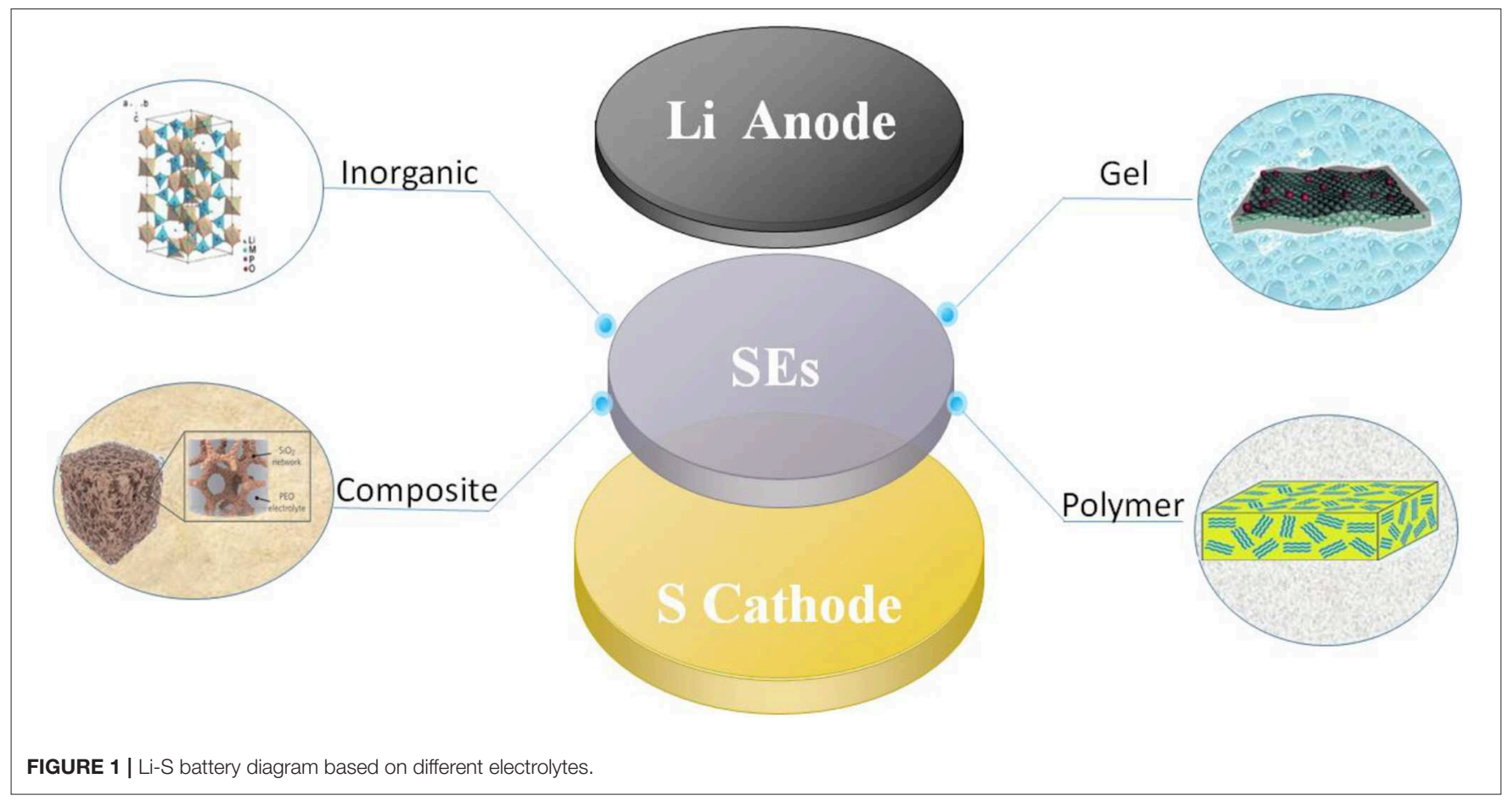

TABLE 1 | Comparison of composition and performance of different electrolytes.

\begin{tabular}{|c|c|c|c|c|c|}
\hline Electrolyte & Composition & $\begin{array}{l}\text { Ionic conductivity } \\
\text { S.cm }{ }^{-1} @ 25^{\circ} \mathrm{C}\end{array}$ & $\begin{array}{l}\text { Mechanical } \\
\text { properties }\end{array}$ & Advantages & Disadvantages \\
\hline Gel & $\begin{array}{l}\text { Polymer + liquid } \\
\text { electrolyte }\end{array}$ & $\sim 10^{-3}$ & General & $\begin{array}{l}\text { High ionic conductivity and Low interfacial } \\
\text { impedance; Suppress LiPSs shuttling to } \\
\text { some extent }\end{array}$ & $\begin{array}{l}\text { Poor thermal stability; Low } \\
\text { mechanical strength }\end{array}$ \\
\hline $\begin{array}{l}\text { Solid-state } \\
\text { polymer }\end{array}$ & $\begin{array}{l}\text { Polymer + lithium salt } \\
+ \text { additive }\end{array}$ & $<10^{-5}$ & Good & $\begin{array}{l}\text { Low interfacial impedance; Good thermal } \\
\text { stability; Suppressing LiPSs shuttling }\end{array}$ & $\begin{array}{l}\text { Low ionic conductivity; Low } \\
\text { mechanical strength }\end{array}$ \\
\hline Inorganic & Inorganic + lithium salt & $10^{-5} 10^{-4}$ & Strong & $\begin{array}{l}\text { High ionic conductivity; Excellent thermal } \\
\text { stability; } \\
\text { Preventing LiPSs shuttling; Suppressing Li } \\
\text { dendrite growth }\end{array}$ & $\begin{array}{l}\text { High interfacial impedance; } \\
\text { Low ionic conductivity }\end{array}$ \\
\hline $\begin{array}{l}\text { Inorganic-organic } \\
\text { composite }\end{array}$ & $\begin{array}{l}\text { Polymer/Organic Fiber } \\
+ \text { Inorganic }\end{array}$ & $10^{-5} 10^{-4}$ & Strong & $\begin{array}{l}\text { Low interfacial impedance; Good thermal } \\
\text { stability; Suppressing LiPSs shuttling; } \\
\text { Suppressing Li dendrite growth }\end{array}$ & Low ionic conductivity \\
\hline
\end{tabular}

adsorption capacity of the polyvinylidene fluoride is poor, and the shuttling effect of the lithium polysulfide intermediates cannot be effectively limited. In order to solve this problem, polar sites are introduced to entrap the dissolved lithium poly-sulfides. The polymer with oxygen-containing functional group and metal oxide particles have been added into the gel polymer electrolyte as fillers to blocks the diffusion effect in the gel electrolyte. By the adding of organic solvents [such as ethylene carbonate (EC), propylene carbonate (PC), dimethyl carbonate (DMC), dimethyl Carbonate (DEC)] and lithium salts in polymer matrices [such as polymethyl methacrylate (PMMA), polyethylene glycol (PEG), Polyethylene oxide (PEO), etc.], Gel polymer electrolyte (GPE) or Gel electrolyte can possess the advantages of the liquid electrolyte and the solid electrolyte (Zhang et al., 2013; Jeddi et al., 2014). It has high ion conductivity $>10^{-4} \mathrm{~S} / \mathrm{cm}$ at room temperature and low interface impedance. The GPE is capable of adsorbing a large amount of liquid electrolyte and isolating the contact between the liquid electrolyte and the sulfur electrode, thereby inhibiting the dissolution of the polysulfide and blocking the "shuttle effect" to some extent.

\section{All-Solid-State Polymer Electrolytes}

The all-solid polymer electrolyte does not contain the liquid electrolyte, which has benefits, such as good thermal stability, high mechanical strength and easy to form film, chemical and electrochemical stability, the ability to perform structural design at the molecular level, etc. It can effectively inhibit the dissolution 
of the polysulfide while the all-solid polymer electrolyte and the electrode are in close contact.

The all-solid polymer electrolyte is usually composed of a polymer matrix with a higher dielectric constant and a lithium salt with a lower lattice energy. Among them, the common polymers are PEO, PMMA, PVDF [Poly(vinylidene fluoride)], PAN (polyaniline) and the like. The ionic conductivity of PAN can reach $10^{-3} \mathrm{~S} / \mathrm{cm}$ at a certain temperature, due to the higher $\mathrm{Li}^{+}$migration number and electrochemical stability window of the PAN, but the disadvantage is that PAN can react with lithium metal anode (Abraham and Alamgir, 1991; Wang et al., 1996; Ryoo et al., 1998). Therefore, it is difficult to apply to lithium sulfur batteries on a large scale. The mechanical properties of PMMA are too low to inhibit the growth of lithium dendrites. PVDF has a high dielectric constant, which can fully ionize the lithium salt, thereby increasing the ionic migration number, but the interfacial stability between PVDF and lithium metal is poor, and the $\mathrm{LiF}$ is generated to cause safety problems (Choe et al., 1995). In the currently studied solid polymer electrolyte(SPE), poly(ethylene oxide) (PEO)-based SPE has good compatibility with electrode interface, excellent electrochemical stability and an acceptable $\mathrm{Li}^{+}$migration number (Scrosati et al., 2001; Hovington et al., 2015). The problem of PEO-based polymer electrolytes remains to be the poor ionic conductivity $\left(<10^{-5}\right.$ $\mathrm{S} / \mathrm{cm}$ ) at room temperature. Therefore, a large number of studies are devoted to exploring the microscopic mechanism of the kinetic transport of the ions in polymers. For PEO-based polymer electrolyte, the dissociation of lithium salt with ether oxygen bonds in the PEO chain, while the chain end motion drives the transport of lithium ions. PEO is amorphous and has satisfactory ionic conductivity above the glass transition temperature but has a relatively low ionic conductivity $\left(10^{-7} \mathrm{~S} \mathrm{~cm}^{-1}\right)$ at room temperature. This is because, at high temperatures (above $60^{\circ} \mathrm{C}$ ), PEO has a similar molecular structure to the polyether liquid electrolyte. Thus, the conductivity can be improved. The $\mathrm{Li}+$ conducting behavior of PEO-based Li-S cells at high temperatures may be similar to that of a typical liquid electrolyte Li-S battery, so it is not effective at inhibiting lithium polysulfide at higher temperatures. In contrast, at room temperature, since PEO has the rigidity of a solid polymer film, lithium dendrite and polysulfide dissolution can be effectively suppressed. Li/PEO/S cells were investigated by in-situ scanning electron microscopy (SEM) and UV-vis spectroscopy at higher temperatures. The results show that the polysulfide will dissolve in the SPE and diffuse into the anode. In addition, the type of polysulfide during discharge is different from the charging process. $\mathrm{S}_{4}^{2-}$ is formed during discharging, but $\mathrm{S}_{6}^{2-}$ is formed during charging. An insulating sulfur-rich layer is formed on the Li metal anode to increase internal resistance and limit capacity. In the past few years, researchers have focused on reducing the glass transition temperature and on increasing the ionic conductivity of PEO at room temperature to achieve high cycle performance of Li-S cells around room temperature.

\section{Inorganic Solid Electrolytes}

Compared with the GPE and the SPE, the inorganic solid electrolyte has excellent thermal stability, low flammability, wide electrochemical window, and can effectively block the shuttle of the polysulfide, and inhibit the growth of lithium dendrites. Moreover, the inorganic solid electrolyte can maintain a good chemical stability over a wide temperature range. The inorganic electrolyte includes the ceramic electrolyte (also referred to as a crystalline electrolyte) and the glass electrolyte (also referred to as an amorphous electrolyte). The ceramic electrolyte is a good conductor of lithium ion, which has high $\mathrm{Li}^{+}$ conductivity and $\mathrm{Li}^{+}$migration number at room temperature, but the preparation process of it is complicated. The glass electrolyte has a large change in composition, so it is easy to obtain a high room temperature ionic conductivity. Therefore, compared to the ceramic electrolyte, the glass electrolyte has the advantages of higher ionic conductivity, conductive isotropic, smaller particle interfacial charge transfer resistance and a more simple preparation process (Lee et al., 2002; Tatsumisago, 2004; $\mathrm{Xu}$ and Wen, 2005).

Many inorganic ceramic solid electrolytes, such as NASICON type electrolytes, perovskite electrolytes and garnet type electrolytes have been studied. The perovskite electrolyte whose chemical formula can be described as $\mathrm{ABO}_{3}$ has a high ionic conductivity $\left(\sim 10^{-3} \mathrm{~S} / \mathrm{cm}\right.$, room temperature). The $\mathrm{Li}_{3 \mathrm{x}} \mathrm{La}_{2 / 3-\mathrm{x}} \mathrm{TiO}_{3}$ (LLTO) is a typical perovskite electrolyte. At the $\mathrm{A}$ site, $\mathrm{Li}^{+}$and $\mathrm{La}^{3+}$ are disorderly distributed between the cubic phases and are sequentially placed between the two perovskite structures. The LLTO type electrolyte exhibits a high electrochemical stability at high potential $(8-9 \mathrm{~V})$ and excellent air stability (Bohnke, 2008). The NASICON type electrolyte has a stable structure and fast ion conductivity. Its chemical formula can be abbreviated as $\mathrm{MA}_{2}\left(\mathrm{BO}_{4}\right)_{3}$ where $\mathrm{M}, \mathrm{A}, \mathrm{B}$ represent metal ions and different vacancy states, respectively. The ionic conductivity of the typical NASICON such as $\mathrm{Li}_{1.3} \mathrm{Ti}_{1.7} \mathrm{Al}_{0.3}\left(\mathrm{PO}_{4}\right)_{3}$ can be as high as $7 \times 10^{-4} \mathrm{~S} / \mathrm{cm}$ at room temperature (Arbi et al., 2007). The basic chemical formula of the garnet-type lithium ion solid electrolyte is $\mathrm{Li}_{5} \mathrm{La}_{3} \mathrm{M}_{2} \mathrm{O}_{12}(\mathrm{M}$ $=\mathrm{Nb}$ or Ta), wherein $\mathrm{Li}_{6} \mathrm{BaLa}_{2} \mathrm{Ta}_{2} \mathrm{O}_{12}$ has an ionic conductivity of $1.69 \times 10^{-5} \mathrm{~S} / \mathrm{cm}$ at $25^{\circ} \mathrm{C}$, a poor ion conduction activation energy $(0.40 \mathrm{eV})$ (Kokal et al., 2012). The ionic conductivity of $\mathrm{Li}_{6.4} \mathrm{La}_{3} \mathrm{Zr}_{1.6} \mathrm{Ta}_{0.6} \mathrm{O}_{12}$ at room temperature is up to $10^{-3}$ $\mathrm{S} / \mathrm{cm}$ (Li et al., 2012). In addition, garnet-type electrolytes have attracted much attention because of the wide electrochemical stability window and high stability relative to the $\mathrm{Li}$ anode. It has been reported that (Li Y. et al., 2017) reduced the interfacial impedance of the solid electrolyte with the lithium negative electrode by adding $2 \mathrm{wt} \%$ of $\mathrm{LiF}$ to $\mathrm{Li}_{6.5} \mathrm{La}_{3} \mathrm{Zr}_{1.5} \mathrm{Ta}_{0.5} \mathrm{O}_{12}$. Han et al. (2017) prepared an ultra-thin $\mathrm{Al}_{2} \mathrm{O}_{3}$ film on the surface of $\mathrm{Li}_{7} \mathrm{La}_{2.75} \mathrm{Ca}_{0.25} \mathrm{Zr}_{1.75} \mathrm{Nb}_{0.25} \mathrm{O}_{17}$ electrolyte with the atomic layer deposition technique, which effectively decreased the interfacial resistance from 1,710 to $1 \Omega / \mathrm{cm}^{2}$. In general, the advantages of inorganic ceramic solid electrolytes are outstanding, however, due to the complicated preparation process, the industrial development is greatly limited.

In order to overcome the shortcomings of ceramic solid electrolytes, researchers have turned their attention to inorganic glass electrolytes. Glass electrolytes have the advantages of anisotropic ionic conductivity, zero grain boundary impedance, easy to form the film, and low cost. Glass electrolytes can be 
divided into two major categories: the oxide-type amorphous electrolyte and the sulfide-type amorphous electrolyte. The former has good electrochemical and thermal stability but the room temperature ionic conductivity is extremely low $\left(10^{-8} \sim 10^{-6} \mathrm{~S} / \mathrm{cm}\right.$ ) (Jing et al., 2017). Conversely, the latter type at room temperature has a higher conductivity $\left(10^{-3} \sim 10^{-4}\right.$ $\mathrm{S} / \mathrm{cm}$ ) but it is very sensitive to the moisture and difficult to prepare. Sulfide glass electrolytes include $\mathrm{Li}_{2} \mathrm{~S}-\mathrm{P}_{2} \mathrm{~S}_{5}, \mathrm{Li}_{2} \mathrm{~S}-\mathrm{SiS}$, and $\mathrm{Li}_{3} \mathrm{PS}_{4}$ (Chen R. et al., 2016; Manthiram et al., 2017).

\section{Inorganic-Organic Composite Solid Electrolytes}

In order to compensate for the shortcomings of inorganic solid electrolytes, researchers have designed a series of inorganicorganic composite electrolytes in combination with the organic electrolytes. Composite electrolytes (CPE) are typically synthesized by chemical or physical methods from ceramic materials to polymers or organic materials such as organic fibers, cellulose, and organic electrolytes. The composite electrolyte contains inorganic and organic moieties that combine the advantages of each material, such as high Li ion conductivity, the good mechanical strength of the inorganic portion, and good interfacial contact of the organic portion. Therefore, the use of the composite electrolyte in the Li-S battery can not only solve the problems associated with the shuttling effect of polysulfide species but also solve the interface contact problem. The interfacial compatibility between the electrolyte and the electrode decreases the interfacial impedance; and the inorganic substance also has the ability to adsorb the polysulfide. Therefore, the inorganic-organic composite electrolyte is expected to simultaneously improve the battery safety and the electrochemical performance. Common composite electrolytes are: polymer-inorganic ceramics, organic liquid-inorganic ceramics, polymer-active fillers, and the like. Generally, complex electrolytes operate at higher temperatures to achieve high ionic conductivity. Among various composite solid electrolytes, PEO-based composite electrolyte is the research focus. Lithiumion conductive nanoparticles, such as $\mathrm{LLZO}, \mathrm{Li}_{0.33} \mathrm{La}_{0.55} 7 \mathrm{TiO}_{3}$ (LLTO), $\mathrm{LiAlO}_{2}$ and $\mathrm{Li}_{10} \mathrm{SnP}_{2} \mathrm{~S}_{12}$ (LSPS), are embedded in the host $\mathrm{PEO}$ polymer matrix to reduce the crystallization of the PEO polymer chain and promote the amorphous region, thereby increasing the ionic conductance rate.

\section{ADVANCES IN SOLID STATE Li-SULFUR BATTERIES}

\section{Li-Sulfur Batteries Based on GPE}

The PVDF-based GPE, prepared by solvent casting and swelling with a liquid electrolyte solution, can effectively stabilize the high-loading (e.g., 70\% S) sulfur composite cathode, reduce the dissolution of sulfur, and slow the diffusion of polysulfide to the anode. And with the GPE based electrolyte, Li-sulfur batteries can achieve a capacity which is close to the theoretical limit of the Li-S battery (1,675 $\mathrm{mA} \mathrm{h} \mathrm{g}^{-1}$ ) (Agostini et al., 2017). Composite gel electrolytes based on PEO and poly(vinylidene fluorideco-hexafluoropropylene) (PVDF-HFP) have also improved the safety and cycle performance of lithium-sulfur batteries (Ho Park et al., 2010; Zhang and Tran, 2013). A novel small molecule of the GPE was prepared by mixing the 1,3-dioxolane, dimethyl ether and the lithium salt. When the mass fraction of small molecules was $8.3 \mathrm{wt} \%$, the ionic conductivity was the highest, reaching $6.43 \times 10^{-3} \mathrm{~S} / \mathrm{cm}$. The initial discharge specific capacity of the sulfur positive electrode at $0.1 \mathrm{C}$ is $1,008 \mathrm{mAh} \mathrm{g}^{-1}$ (Zhu et al., 2017). Wu et al. (2016) designed a novel sandwich layered polymer electrolyte, in which the PVDF layer absorbs a large amount of ether-based liquid electrolyte, thereby increasing the migration of Li ions, and the PMMA layer prevents the liquid electrolyte from reacting with the metal lithium. The initial capacity of the lithium-sulfur battery based on the GPE reaches $1711.8 \mathrm{mAh} \mathrm{g}^{-1}$ and has a good cycle performance. This "sandwich" GPE provides a new idea for the design of the electrolyte structure of lithium-sulfur batteries. In addition to the PVDF, the PMMA is also a good candidate for gel polymer. The electrospun polypropylene eye (PAN)/PMMA film absorbing the polyethylene glycol dimethyl ether (PEGDME) and the lithium salt is used as the electrolyte, and the composite material of carbon nanotubes and sulfur is used as the positive electrode. The excellent chemical compatibility between the PAN/PMMA film and the sulfur cathode improves the conductivity of the positive electrode and suppresses the shuttle of the polysulfide, thereby improving the electrochemical performance (Rao et al., 2012). There is also a report on the preparation of a novel gel polymer consisting of an alkyl carbonate mixture solution and a lithium salt dispersed in PVDF-HFP/PMMA (Zhao et al., 2013; Zhang Y. et al., 2014). The poly(vinylidene fluoride) (PVDF)-based gel polymer electrolyte (GPE), with a dense morphology, was prepared using a simple solution casting method, incorporating the poly(ethylene oxide) and the nano-zirconia to improve the absorption of the liquid electrolyte and the $\mathrm{Li}^{+}$mobility (Gao et al., 2017) (Figure 2A).

The in-situ synthesis method has the characteristics of simple process and low cost, which provides the possibility of realizing the large-scale application of the solid electrolyte for highperformance lithium-sulfur battery. The in-situ synthesized pentaerythritol tetra-acrylate (PETEA)-based GPE has an ionic conductivity of $1.13 \times 10-2 \mathrm{~S} / \mathrm{cm}$ at room temperature, and the electrolyte/electrode interface is tightly bonded leading the good compatibility, which in turn decreases the impedance of the interface (Liu et al., 2016). At the same time, a flexible and stable passivation layer is formed on the surface of the sulfur electrode, which can limit the movement of the polysulfide (Figure 2B) and improve the cycle performance of the lithiumsulfur battery. The polysulfide can also be used as an additive for gel electrolytes (Agostini and Hassoun, 2015), resulting in a significant improvement in the performance of the electrolyte (Figure 2C). In order to improve the room temperature ionic conductivity of GPEs, some optimization of GPEs is conducted. For example, ball milling of GPEs can cause certain changes in microstructure and promote the ionic interactions, thereby improving the ionic conductivity (Shin et al., 2002a). In addition, decreasing the crystallinity of the gel polymer can also increase the ionic conductivity. The ionic conductivity of the crosslinked amorphous polyepichlorohydrin terpolymer-based GPE reached 

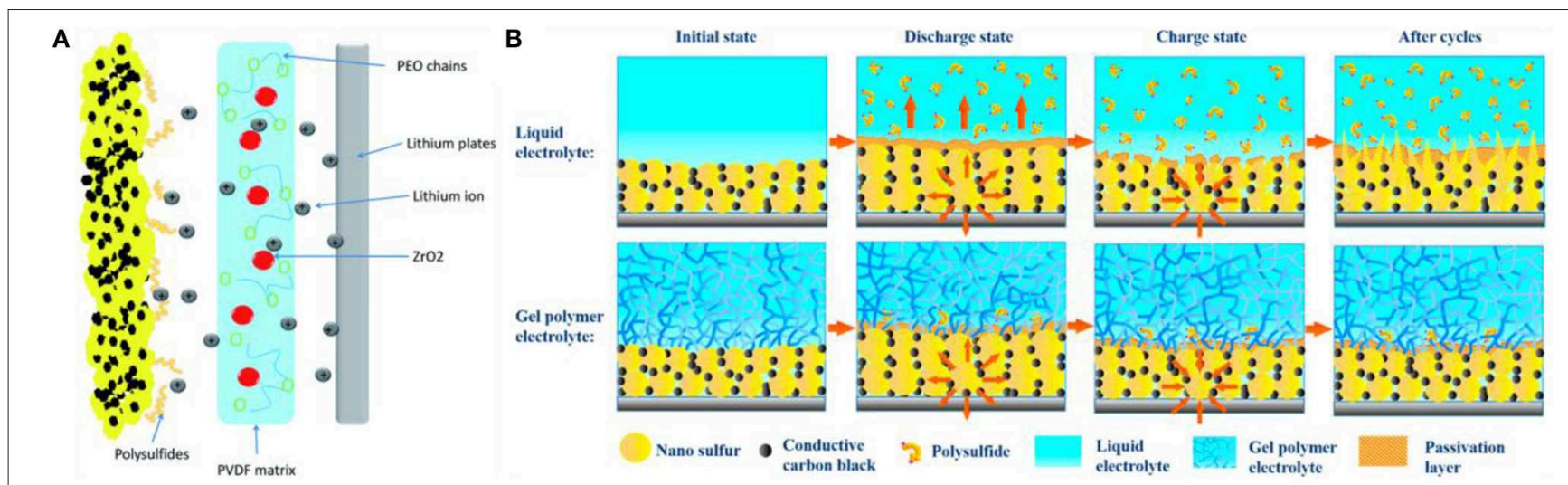

C

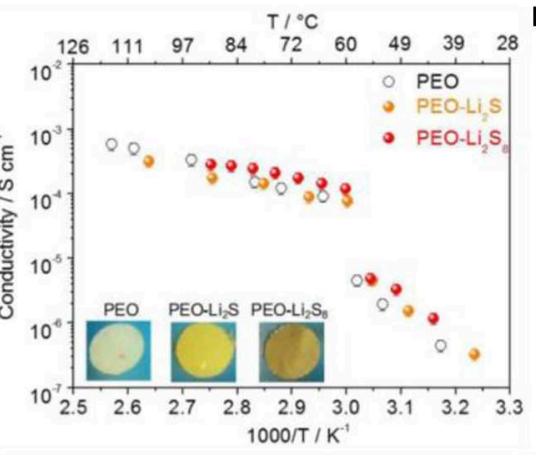

D

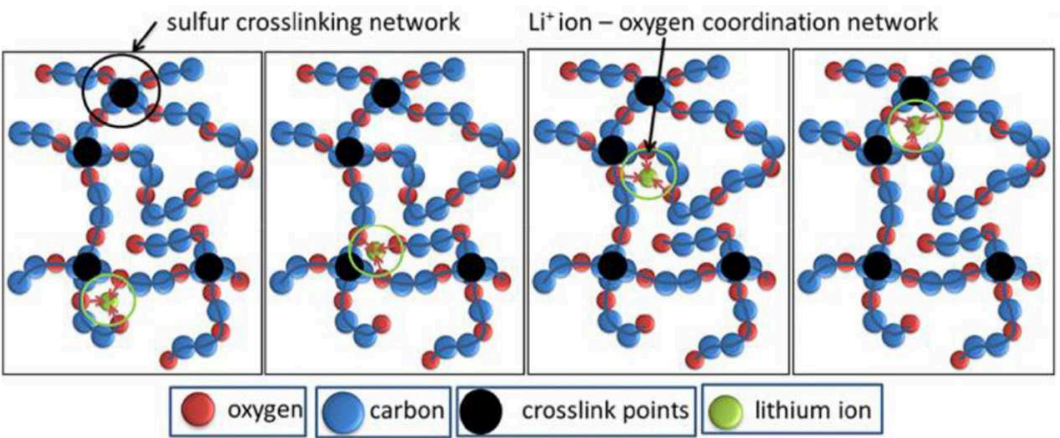

E
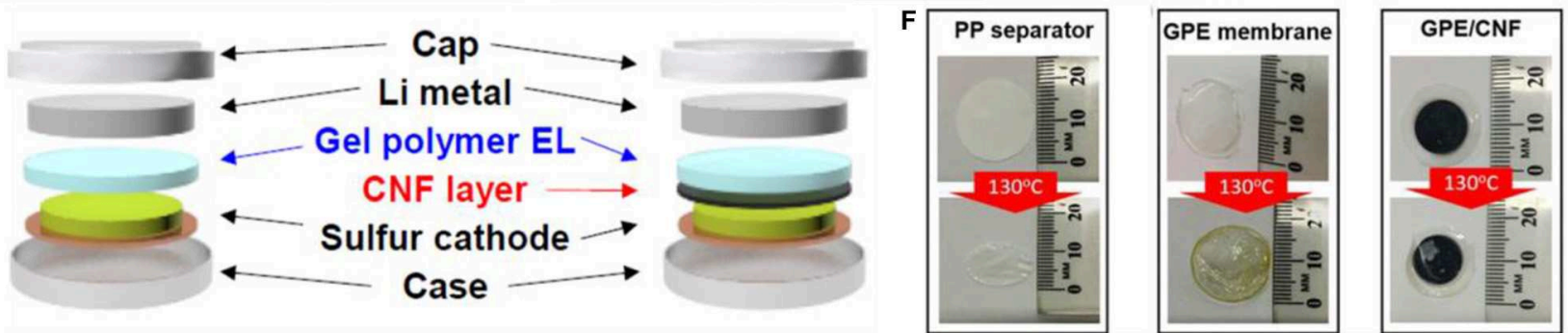

FIGURE 2 | Li-sulfur batteries based on gel polymer electrolyte (GPE). (A) The illustration of $\mathrm{Li}^{+}$ion transport and polysulfide blocking mechanism for the membrane of PPZr-GPE. Reproduced with permission (Nair et al., 2016). Copyright 2017, Journal of Materials Chemistry A. (B) The immobilization mechanism for polysulfide. Reproduced with permission (Zhang et al., 2013). Copyright 2016, Nano Energy. (C) Temperature dependence of the ionic conductivity for PEO, PEO-Li2S and $\mathrm{PEO}-\mathrm{Li}_{2} \mathrm{~S}_{8}$ electrolytes and, in inset, the photographic images of the membranes (PEO, white color; PEO-Li $2 \mathrm{~S}$, yellow color; PEO-Li $\mathrm{i}_{8}$, red color). Reproduced with permission (Rao et al., 2015). Copyriht 2015, Sci Rep. (D) Illustration of a classical sulfur cross-linking structure as well as lithium ion-oxygen coordination structure. A possible lithium ion transportation mechanism is also described. Reproduced with permission (Jin et al., 2012) Copyright 2017, Polymer. (E) Schematic illustration of coin cells incorporated with GPE and GPE/CNF membrane, respectively. (F) PP separator, GPE membrane, and GPE/CNF membrane before and after thermal treatment. (E,F) Reproduced with permission (Baloch et al., 2016). Copyright 2017, Chemistry-An Asian Journal.

$10^{-3} \mathrm{~S} / \mathrm{cm}$ at room temperature (Figure 2D; Choudhury et al., 2017). The nano-scale microfibrillated cellulose is prepared by a thermally induced polymerization method and can be used as the support for GPE electrolyte, which exhibits excellent ionic conductivity, thermal stability and interfacial stability (Nair et al., 2016). Based on the polyimide (PI)-based electrospun polymer film, a new type of GPE was prepared by activating the PVDFHFP and further coating the nano- $\mathrm{Al}_{2} \mathrm{O}_{3}$. The specific capacity of the Li-S battery can still reach $820 \mathrm{mAh} \mathrm{g}^{-1}$ after more than 100 cycles (Rao et al., 2015). A free-standing trimethylolpropane ethoxylate triacrylate gel polymer electrolyte was synthesized by the chemical crosslinking method, and the crosslinked gel polymer electrolyte (Figures 2E,F) exhibited an excellent thermal stability at a high temperature of $130^{\circ} \mathrm{C}$. Moreover, the GPE combined with carbon nanofibers ( $\mathrm{CNFs}$ ) can effectively prevent the polysulfide dissolution and enhance the electrochemical properties, including the high capacity of $1,177 \mathrm{mAh} \mathrm{g}^{-1}$ in the first cycle and the capacity retention of $64 \%$ after 300 cycles (Choi et al., 2017).

Although GPEs are physically able to block the transfer of the polysulfide, the dissolution of the polysulfide is still present due to the employment of the liquid electrolyte. Recently, ionic liquids (ILs) have been found to be an attractive addition for GPE because the combination of ILs and GPE can effectively 
control the polysulfide diffusion and protect the lithium metal from reacting with the dissolved polysulfides and electrolyte solvents (Shin and Cairns, 2008; Jin et al., 2012; Rao et al., 2012). Many studies have shown that this mixed electrolyte can also decrease the crystallinity of the polymer and improve the thermal/chemical stability of the electrolyte. 1-propyl3-methylimidazolium bis(trifluoromethanesulfonyl)imide (PMImTFSI) was used for GPE (Kim, 2017), based on which the Li-S battery has an initial discharge capacity of $1,029 \mathrm{mAh} / \mathrm{g}$ at $0.1 \mathrm{C}$ and $885 \mathrm{mAh} \mathrm{g}^{-1}$ after 30 cycles. The gel polymer electrolyte (GPE), combining the porous membrane with the $\mathrm{N}$ methyl-N-butyl pyrrolidine bis (trifluoromethanesulfonyl)imide ionic liquid, exhibited good thermal stability and excellent interfacial stability (Baloch et al., 2016). The corresponding lithium-sulfur battery provided an initial discharge capacity of $1217.7 \mathrm{mAh} \mathrm{g}^{-1}$ and maintained a reversible capacity of $818 \mathrm{mAh} \mathrm{g}^{-1}$ after 20 cycles at a current density of $50 \mathrm{~mA}$ $\mathrm{g}^{-1}$ (Jin et al., 2012). Cheng et al. (2018) proposed a novel gel polymer electrolyte (GPE) in which a nanostructured ionic liquid (IL) was introduced into the gel polymer electrolyte matrix prepared by electrospinning. After bonding with the nanostructured IL, the new GPE exhibited good mechanical properties, improved the absorption of the electrolyte (552 wt \%), and had an ionic conductivity up to $0.64 \mathrm{mS} \mathrm{cm}^{-1}$ at room temperature, as well as a high lithium ion transfer number $\left(\mathrm{t}_{\mathrm{Li}+}=0.60\right)$.

It can be seen from the above analyses that the GPE has high ionic conductivity at room temperature, good interfacial contact, and can significantly inhibit the shuttle of the polysulfide, which can significantly improve the cycle life of lithium-sulfur batteries. However, the GPE still contains a certain amount of liquid electrolyte, which is difficult to fundamentally solve various problems of liquid electrolyte, such as the polysulfide shuttle and poor thermal stability. It is necessary to further study the polymerization mechanism pf the precursor and the in-situ synthesis method, giving full play to the advantages of lower GPE interface impedance and higher ionic conductivity.

\section{Li-S Batteries Based on Solid Polymer Electrolyte}

At room temperature, the polymer electrolyte like PEO usually has the poor ionic conductivity due to the high crystallinity and the high glass transition temperature (Verma et al., 2014b). In order to decrease the crystallinity and the glass transition temperature to obtain PEO-based electrolytes with high ionic conductivity, researchers have conducted extensive researches and have found that adding certain inorganic fillers, such as oxides and sulfides to polymer electrolytes, can effectively enhance the ionic conductivity. The glass transition temperature decreases with the increase of the amorphous region, thereby increasing the ionic conductivity and the mechanical strength at room temperature (Croce et al., 1998). The (PEO) ${ }_{20}$ LiTFSI$10 \%(w) \gamma-\mathrm{LiAlO}_{2}$ type SPE was applied to a lithium-sulfur battery (Zhu et al., 2005), showing an initial discharge specific capacity of $450 \mathrm{mAh} \mathrm{g}^{-1}$ at a current density of $0.1 \mathrm{C}$. Subsequently (PEO) ${ }_{18} \mathrm{LiTFSI}-10 \%(\mathrm{w}) \mathrm{SiO}_{2}$ type SPE was used in a lithium-sulfur battery whose positive electrode material was sulfur/mesoporous carbon sphere, and the first discharge specific capacity was 1,265 $\mathrm{mAh} \mathrm{g}^{-1}$ (Liang et al., 2011a).

Typical oxide fillers such as $\mathrm{TiO}_{2}, \mathrm{Al}_{2} \mathrm{O}_{3}, \mathrm{SiO}_{2}$ (Verma et al., 2014a) and $\mathrm{ZrO}_{2}$ are widely used in all-solid-state polymer Li$\mathrm{S}$ batteries, Liang (1973) added the $\mathrm{A}_{2} \mathrm{O}_{3}$ to polycrystalline LiI to conduct ion without chemical reaction. To explain this phenomenon, Maier (1995) proposed a space charge effect, which is believed that can affect the ionic conductivity of the two-phase interface, so that the ionic conductivity can be improved by introducing an inert ceramic filler into the inorganic polymer. Bronstein et al. synthesized a novel hybrid solid polymer electrolyte consisting of organically modified aluminum silicon (OM-AlSi) formed in the PEO-LiTFSI phase, which was highly effective in increasing the dielectric constant and ionic conductivity (Bronstein et al., 2004). Shin et al. (2002b) added titanium oxide $\left(\mathrm{TinO}_{2 \mathrm{n}-1}, n=1,2\right)$ to PEO [lithium bis(fluorosulfonyl)-imide] (LiFSI) SPE, which could increase the ionic conductivity of PEO-based SPE and improve the interfacial stability between the $\mathrm{Li}$ metal anode and the SPE. The research group also prepared nano- $\mathrm{Al}_{2} \mathrm{O}_{3}$ as a filler of $\mathrm{PEO}\left(\mathrm{LiBF}_{4}\right) \mathrm{SPE}$ by ball milling. It was found that the addition of $\mathrm{Al}_{2} \mathrm{O}_{3}$ filler decreased the spherulite size and crystallinity of PEO, thus improving the ionic conductivity of the PEObased electrolyte (Jeong et al., 2005). As well as that, the solid polymer electrolyte prepared with $\mathrm{Al}_{2} \mathrm{O}_{3}$ filler improved the cycle performance of lithium-sulfur batteries (Jeong et al., 2007). This is because the unique structure of PEO- $\mathrm{Al}_{2} \mathrm{O}_{3}$-based SPE allows the free transport of lithium ions and prevents the transport of polysulfide anions through the physical absorption and electrochemical deposition, which can effectively reduce the shuttle effect and the loss of active materials (Zhang Z. et al., 2014). Bing-joe Hwang et al. also added $\mathrm{TiO}_{2}$ to the PEObased solid electrolyte improving the performance of the battery effectively (Lee et al., 2017) (Figure 3A). The specific capacity of the polymer electrolyte with nano-sized $\mathrm{TiO}_{2}$ is $>1,450 \mathrm{mAh} \mathrm{g}^{-1}$, and the capacity retention after 100 cycles is $87 \%$. In contrast, the capacity retention using the pure PEO is $38 \%$. Calculations and Raman measurements indicate that nano-sized $\mathrm{TiO}_{2}$ particles can interact with and anchor to polysulfide species through adsorption mechanisms, preventing them from diffusing to the $\mathrm{Li}$ anode (Figures 3B,C). Besides, the incorporation of $\mathrm{TiO}_{2}$ nanoparticles increases the amorphous phase of PEO and the ionic conductivity.

In addition to oxides, sulfides and other inorganic materials are often used as fillers for polymer electrolytes in all-solid lithium sulfur batteries. Hassoun and Scrosati (2010) prepared a SPE film by hot pressing PEO (LiFSI) with adding the nano $\mathrm{ZrO}_{2}$ and $\mathrm{Li}_{2} \mathrm{~S}$ to stabilize the $\mathrm{Li}$ metal anode/electrolyte interface, while increasing the ionic conductivity and $\mathrm{Li}+$ transfer number. Sheng et al. (2017) prepared novel poly(ethylene oxide) (PEO) solid polymer electrolytes (SSPEs) containing ionic liquid grafted oxide nanoparticles (IL@NPs) (Figure 3D), and the IL containing $\mathrm{Cl}^{-}$increased the free lithium ion conductivity by weakening the interaction between the lithium ion and the PEO chain. At the same time, the ion-grafted oxide nanoparticles also increased the ion channel leading the high ionic conductivity at low 


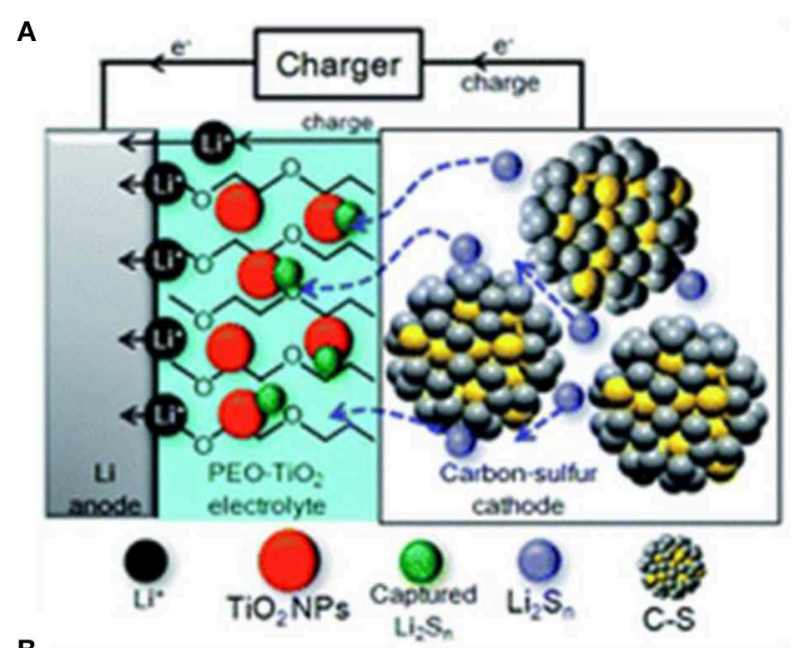

B

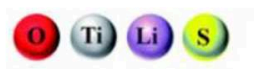

Anatase $\mathrm{TiO}_{2}$ (101)

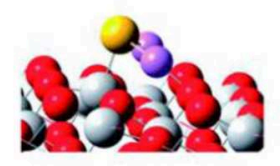

$\mathbf{L i}_{2} \mathbf{S}$

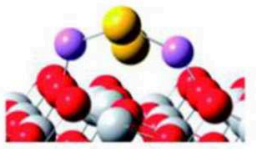

$\mathrm{Li}_{2} \mathrm{~S}_{2}$
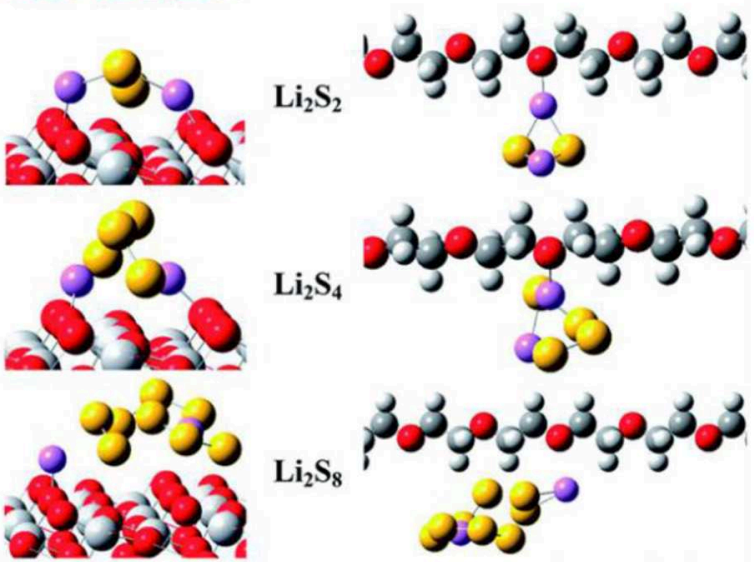

$\mathrm{Li}_{2} \mathrm{~S}_{8}$

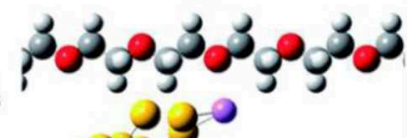

205
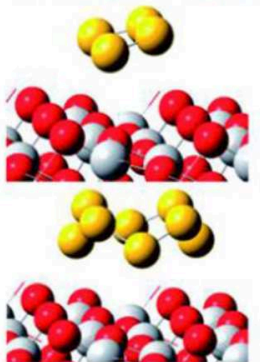

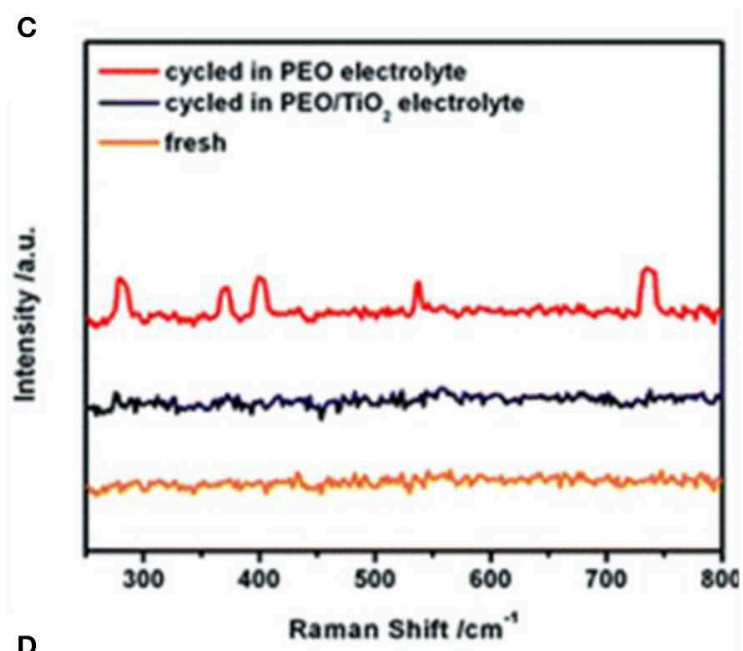

D

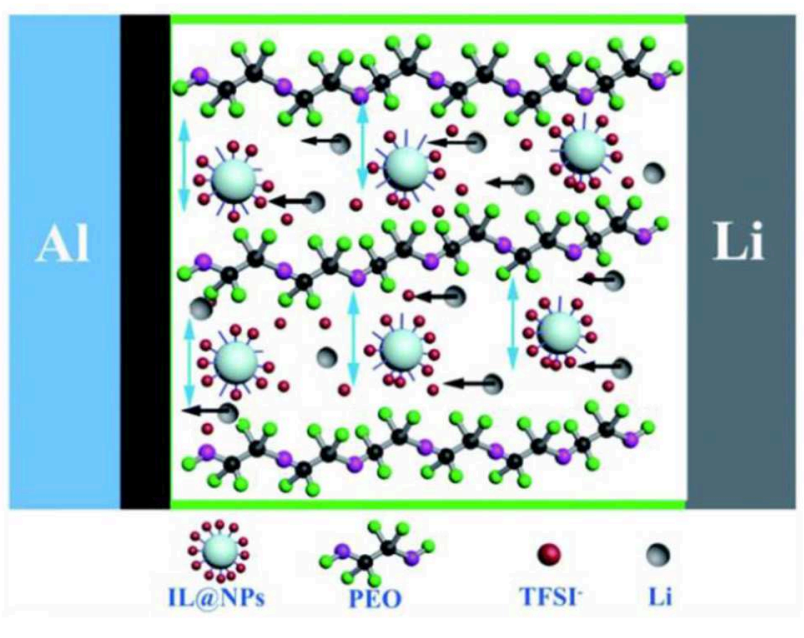

E

Ionic conductivity $\left(10^{-4} \mathrm{~S}\right.$

$\mathrm{cm}^{-1}$ ) Electrochemical window (V vs Samples $\left.298 \mathrm{~K} 310 \mathrm{~K} 323 \mathrm{~K} 353 \mathrm{~K} \mathrm{Li} \mathrm{L}^{+} / \mathrm{Li}\right)$

\begin{tabular}{llllll}
\hline PEO-Li & 0.092 & 0.413 & 1.07 & 3.01 & 4.3
\end{tabular}

PEO-Li- $\begin{array}{lllll}0.221 & 0.715 & 1.84 & 4.52 & 4.8\end{array}$

Si

PEO-Li- $0.423 \quad 1.298 \quad 3.14 \quad 9.15 \quad 4.9$

$\mathrm{Ti}$

PEO-Li- $0.854 \quad 2.315 \quad 4.95 \quad 15.2 \quad 4.9$

$\mathrm{Zr}$

FIGURE 3 | Solid polymer electrolyte. (A) Equivalent circuit for impedance simulation and impedance measurements on $\mathrm{PEO}$ and $\mathrm{PEO} / \mathrm{TiO} 2$ electrolytes after cycling. Reproduced with permission (Sheng et al., 2017). Copyright 2017, Journal of Materials Chemistry A. (B) The adsorption configuration of lithium polysulfide ( $\mathrm{L}_{2} \mathrm{~S}_{\mathrm{n}}$ ) and sulfur species on the PEO chain and anatase- $\mathrm{TiO}_{2}$ (101). (C) Raman spectra of the $\mathrm{Li}$ anode, $\mathrm{PEO}$ and $\mathrm{PEO} / \mathrm{TiO} 2$ electrolytes before and after cycling.

(B,C) Reproduced with permission (Sheng et al., 2017). Copyright 2017, Journal of Materials Chemistry A. (D) Schematic illustration of the promotion of the

lithium-ion transportation. (E) lonic conductivities and electrochemical windows of polymer electrolytes. (D,E) Reproduced with permission (Zhang C. et al., 2015).

Copyright 2017, Journal of Materials Chemistry A. 
temperatures. In addition, the difference between the IL@NPs based on $\mathrm{ZrO}_{2}, \mathrm{TiO}_{2}$, and $\mathrm{SiO}_{2}$ was compared (Figure 3E). Among these modified electrolytes, the $\mathrm{ZrO}_{2}$ filled electrolyte has the highest ionic conductivity. Similarly, the Lewis acidic metal-organic framework [MIL-53 (Al)] can be added to the polymer electrolyte to improve the cell performance (Zhu et al., 2014). MIL-53 (Al) was used as the filler for polyethylene oxide (PEO) based SPE. With the participation of MIL-53 (Al), the ionic conductivity of the solid electrolyte increased from 9.66 $\times 10^{-4} \mathrm{~S} / \mathrm{cm}$ to $3.39 \times 10^{-3} \mathrm{~S} / \mathrm{cm}$ at $120^{\circ} \mathrm{C}$, and the oxidation potential increased from $4.99 \mathrm{~V}$ to $5.10 \mathrm{~V}$. Simultaneously, the addition of MIL-53 (Al) can effectively inhibit the dissolution and shuttle of the polysulfide in all-solid lithium-sulfur batteries. The discharge capacity at 0.2 and $80^{\circ} \mathrm{C}$ is $1,520 \mathrm{~mA} \mathrm{~h} / \mathrm{g}$, and the 1,000 th cycle discharge capacity at $4 \mathrm{C}$ is still as high as $325 \mathrm{~mA}$ $\mathrm{h} \mathrm{g}^{-1}$, indicating that the battery has excellent rate performance and cycle life (Zhang C. et al., 2015). According to the EIS spectrum, there was no semicircle caused by the polysulfide shuttle and the electrolyte/Li interface reaction, demonstrating that the polysulfide did not dissolve. After 10 discharge/charge cycles, the XPS spectrum on the surface of the $\mathrm{Li}$ anode showed that the sulfur and polysulfide didn't transfer from the cathode to the anode. The group also used the natural halloysite nanotubes (HNT) as the solid electrolyte filler. Lithium ions were immobilized on the outer tube wall (negative electrode) of HNT with a 3D channel structure. The $\mathrm{TFSI}^{-}$anion was adsorbed on the inner tube wall (positive electrode). Since the surface of the HNT particles has the charge opposite to that of the lithium salt, the dissociation of the lithium salt is promoted, and the $3 \mathrm{D}$ channel accelerates the transmission of $\mathrm{Li}^{+}$(Lin et al., 2017). Zhang Y. et al. (2015) fabricated a solid polymer electrolyte using PEO, LiTFSI and montmorillonite (MMT). The PEO-based solid electrolyte containing $10 \mathrm{wt} \%$ of MMT exhibited an ion conductivity of $3.22 \times 10^{-4} \mathrm{~S} / \mathrm{cm}$ at $60^{\circ} \mathrm{C}$, which satisfied the operational requirements of the all-solid lithium-sulfur battery. An initial discharge capacity of $998 \mathrm{mAh} \mathrm{g}^{-1}$ was provided at $0.1 \mathrm{C}$, and a reversible specific discharge capacity of $634 \mathrm{mAh} \mathrm{g}^{-1}$ was still available after 100 cycles.

Apart from adding inorganic fillers, the design of the molecular structure also has a great effect on the performance of the PEO-based SPE. The PEO forming the pleated structure by the cross-linking method improves the mechanical strength while decreasing the crystallinity. Ben Youcef et al. (2016) prepared a SPE with semi-interpenetrating network by UV-induced the cross-linking of poly(ethylene glycol) diacrylate (PEGDA) and divinylbenzene (DVB) in a PEO (LiTFSI) matrix. The addition of DVB crosslinker decreased the crystallinity of PEO from 34 to $23 \%$ and the melting temperature from 50 to $34^{\circ} \mathrm{C}$. The SPE showed a high electrochemical stability of $4.3 \mathrm{~V}$. The actual conductivity value exceeds $10^{-4} \mathrm{~S} / \mathrm{cm}$ at $70^{\circ} \mathrm{C}$.

In summary, all solid polymer electrolytes, such as PEO based electrolyte and its derivatives, have the disadvantage of poor ionic conductivity at room temperature, the battery based on which generally needs to operate at high temperatures. Such polymer electrolytes become viscoelastic at high temperatures and migrate through the polymer segments to drive their coordinated lithium ions. In addition, the mechanical strength of PEO-based polymer electrolytes at high temperatures is decreased, and the short circuits of the battery are likely to occur (Agrawal and Pandey, 2008). In order to realize the practical application of the polymer solid electrolyte, it is necessary to further increase the room temperature ionic conductivity of the polymer, develop a single ion conductor polymer electrolyte with ion mobility close to 1 , and improve the mechanical properties of the polymer solid electrolyte.

\section{Li-S Batteries Based on Inorganic Solid Electrolyte}

$\mathrm{Fu}$ et al. (2017a) reported for the first time a 3D doublelayer garnet electrolyte (Figure 4A). The thickness of the dense layer reduced to a few microns and still maintained good mechanical stability. The thicker porous layer acts as a mechanical support for the thin dense layer and a body for the high loading cathode material. The Li-S battery exhibited high initial coulombic efficiency $(>99.8 \%)$ and high average coulombic efficiency (>99\%) in subsequent cycles. Recently, Yu et al. (2016) applied another NASICON-type lithium ion conductor, $\mathrm{Li}_{1+\mathrm{x}} \mathrm{Y}_{\mathrm{x}} \mathrm{Zr}_{2-\mathrm{x}}\left(\mathrm{PO}_{4}\right)_{3}$ (LYZP) as a solid-electrolyte (Figure 4B). The initial discharge capacity of the Li-S battery assembled with this oxide solid electrolyte reached 1,100 $\mathrm{mAh}$ $\mathrm{g}^{-1}$ and retained $\sim 90 \%$ of the initial capacity after 150 cycles at $0.2 \mathrm{C}$.

Recently, Machida et al. (2004) studied the lithium-sulfur battery based on $\mathrm{Cu}_{2} \mathrm{~S} / \mathrm{S}$ cathode and the solid electrolyte of $\mathrm{Li}_{2} \mathrm{~S}-\mathrm{SiS}_{2}$. The first cycle discharge had a specific capacity of $480 \mathrm{mAh} \mathrm{g}^{-1}$, which was higher than the theoretical capacity of $\mathrm{Cu}_{2} \mathrm{~S}$. Similarly, Hayashi et al. (2003) successfully prepared an all-solid-state battery using a sulfur-based cathode material and a $\mathrm{Li}_{2} \mathrm{~S}-\mathrm{P}_{2} \mathrm{~S}_{5}$ glass-ceramic electrolyte, which showed good cycle performance at room temperature. The battery maintained a high capacity of more than $650 \mathrm{mAh} \mathrm{g}^{-1}$ after 20 cycles. Zhang et al. (2017) obtained a glass phase of $\mathrm{xLi}_{2} \mathrm{~S}-(100-$ $\mathrm{x}) \mathrm{P}_{2} \mathrm{~S}_{5}(65 \leq x \leq 75, \mathrm{~mol} \%)$ by the mechanical ball milling, followed by rapid quenching and tempering. Among them, the $70 \mathrm{Li}_{2} \mathrm{~S} \cdot 30 \mathrm{P}_{2} \mathrm{~S}_{5}$ sample showed the ionic conductivity up to $1.58 \times 10^{-3} \mathrm{~S} / \mathrm{cm}$ (Figure $4 \mathrm{C}$ ). The excellent performance is attributed to the precipitation and heat treatment of the high conductivity thio-LISICON III phase, which reduces the grain boundary and improves the grain morphology. The lithium-sulfur battery with $70 \mathrm{Li}_{2} \mathrm{~S} \cdot 30 \mathrm{P}_{2} \mathrm{~S}_{5}$ glass ceramic as the solid electrolyte has the first discharge specific capacity of $1,055 \mathrm{mAh}^{-1}$ and has excellent coulombic efficiency. Hayashi et al. (2008) constituted an all-solid battery adopting the $\mathrm{Li}_{2} \mathrm{~S}-\mathrm{Cu}$ composite electrode prepared by the mechanical milling method and the $\mathrm{Li}_{2} \mathrm{~S}-\mathrm{P}_{2} \mathrm{~S}_{5}$ glass ceramic electrolyte. The first cycle showed a specific discharge capacity up to $490 \mathrm{mAh}^{-1}$. Xu et al. (2017) studied the $\mathrm{MoS}_{2}$-doped $\mathrm{Li}_{2} \mathrm{~S}-\mathrm{P}_{2} \mathrm{~S}_{5}$ glass ceramic electrolyte $\left(\mathrm{Li}_{7} \mathrm{P}_{2.9} \mathrm{~S}_{10.85} \mathrm{Mo}_{0.01}\right)$, which exhibited an ionic conductivity of $4.8 \times 10^{-3} \mathrm{~S} / \mathrm{cm}$ at room temperature and a wide electrochemical window as high as $5 \mathrm{~V}$ (relative to $\mathrm{Li} / \mathrm{Li}^{+}$). In order to prove the high stability of the $\mathrm{MoS}_{2}$-doped electrolyte with the lithium metal, the allsolid lithium-sulfur battery was assembled with $\mathrm{Li}_{7} \mathrm{P}_{3} \mathrm{~S}_{11}$ and 
A

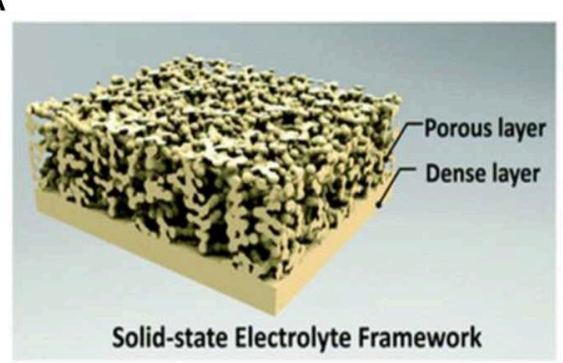

D

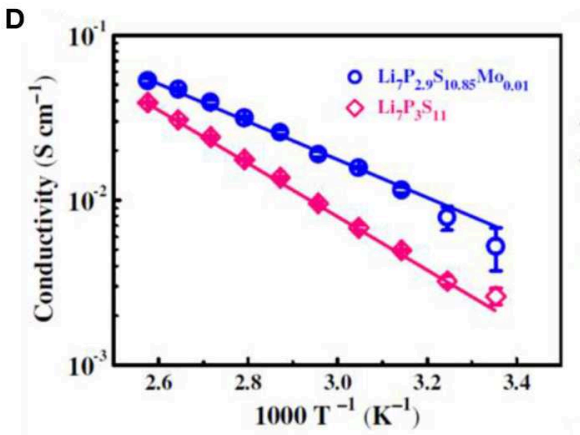

B

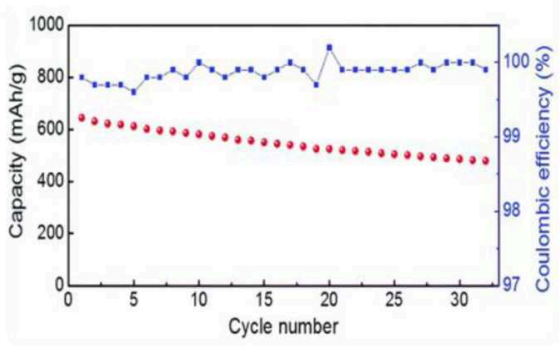

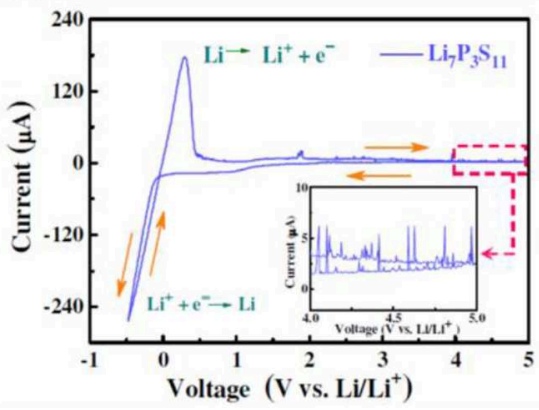

C

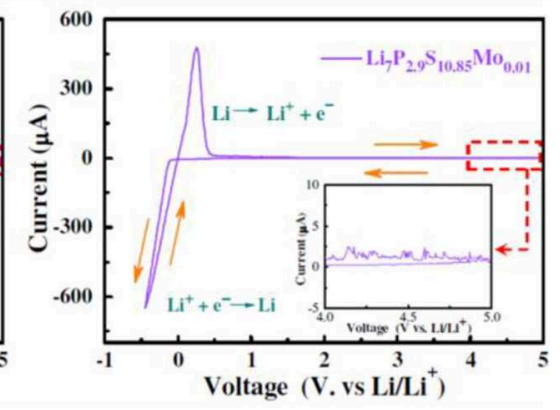

FIGURE 4 | Inorganic solid electrolyte (A) Schematic of the garnet bilayer framework. (B) Cycling performance of the hybrid bilayer Li-S cell with a high sulfur mass loading of approximately $7.5 \mathrm{mg} \mathrm{cm}^{-2}$ at $0.2 \mathrm{~mA} \mathrm{~cm}^{-2}$. Reproduced with permission (Machida et al., 2004). Copyright 2016, Advanced Energy Materials. (C) Conductivity map for $x \mathrm{Li}_{2} \mathrm{~S} \cdot(100-\mathrm{x}) \mathrm{P}_{2} \mathrm{~S}_{5}(\mathrm{x}=65,67.5,70,72.5,75)$ ball-milling glass, quenched glass and heat-treatment glass ceramic at room temperature. Reproduced with permission (Xu et al., 2017). Copyright 2017, Solid State lonics. (D) Arrhenius conductivity plots of Li $\mathrm{P}_{3} \mathrm{~S}_{11}$ and Li $\mathrm{i}_{7} \mathrm{P}_{2.9} \mathrm{~S}_{10.85} \mathrm{Mo}_{0.01}$ at temperatures from 298 to $388 \mathrm{~K}$ and the corresponding CV curves of Li metal cells show the electrochemical window. Reproduced with permission (Kobayashi et al., 2008). Copyright 2017, Journal of Materials Chemistry A.

$\mathrm{Li}_{7} \mathrm{P}_{2.9} \mathrm{~S}_{10.85} \mathrm{Mo}_{0.01}$ as solid electrolytes, respectively. The Li$\mathrm{S}$ battery with $\mathrm{Li}_{7} \mathrm{P}_{2.9} \mathrm{~S}_{10.85} \mathrm{Mo}_{0.01}$ electrolyte showed a high discharge capacity of $1,020 \mathrm{mAh} \mathrm{g}^{-1}$, which was superior to that of the $\mathrm{Li}_{7} \mathrm{P}_{3} \mathrm{~S}_{11}$ electrolyte (Figure 4D).

In order to improve the interface problem between the electrode and the electrolyte, and further improve the utilization of the active material simultaneously, the sulfide electrolyte is often used as the cathode additive to prepare the composite electrode (Kobayashi et al., 2008; Agostini et al., 2013). However, this type of electrolyte has a low ionic conductivity. In order to increase the ionic conductivity, Nagata and Chikusa (2016) added the LiI to the $\mathrm{Li}_{1.5} \mathrm{PS}_{3.3}$ solid electrolyte for the first time, which improved the ionic conductivity effectively. Kato et al. (2016) reported a new sulfide-type lithium ion fast conductor (LISICON) solid electrolyte $\mathrm{Li}_{9.45} \mathrm{Si}_{1.74} \mathrm{P}_{1.44} \mathrm{~S}_{11.7} \mathrm{C}_{10.3}$ with ultra-high conductivity $\left(2.5 \times 10^{-2} \mathrm{~S} / \mathrm{cm}\right)$ and high electrochemical stability. The crystal structure of the $\mathrm{Li}_{10} \mathrm{GeP}_{2} \mathrm{~S}_{12}$ (LGPS) is shown in the figure, and its ionic conductivity is the highest among the existing LISICON solid electrolytes. In general, the inorganic solid electrolyte has the high transfer number of lithium ions higher than that of SPE and GPE, high ionic conductivity at room temperature and the ability of theoretically completely blocking the diffusion of $\mathrm{S}_{\mathrm{n}}^{2-}(4$ $\leq n \leq 8$ ) to the metal lithium negative electrode. However, the inorganic solid electrolyte also has many disadvantages, including a difficult preparation process, low mechanical strength, and large interface impedance with the electrode, which all limit the practical application of the inorganic solid electrolyte. Thus, we need to find a higher quality composite solid electrolyte to solve the above shortcomings.

\section{Li-Sulfur Batteries Based on Composite Electrolyte}

So far, researchers have found a large number of active inorganic fillers that can increase the ionic conductivity of solid electrolytes. The active filler itself has the ionic conductivity and can be used as the solid electrolyte alone. Typically, researchers add the active fillers to the all-solid polymer electrolyte to form a polymer-active filler composite electrolyte to further enhance the performance of all-solid-state batteries. Capuano (1991) firstly combined the spherical active filler $\gamma-\mathrm{LiAlO}_{2}$ with a diameter of $<1 \mu \mathrm{m}$ with the $\mathrm{PEO}$ and the $\mathrm{LiClO}_{4}$ to prepare a composite solid electrolyte, and found that the performance using this composite electrolyte was greatly improved. Choi et al. (2015) fabricated a composite electrolyte complexing the tetragonal phase of $\mathrm{Li}_{7} \mathrm{La}_{3} \mathrm{Zr}_{2} \mathrm{O}_{12}$ with a PEO matrix, which showed a ionic conductivity as high as 4.42 $\times 10^{-4} \mathrm{~S} / \mathrm{cm}$ at $55^{\circ} \mathrm{C}$.

The $\mathrm{Li}_{10} \mathrm{GeP}_{2} \mathrm{~S}_{12}$ with a very high ionic conductivity $\left(10^{-2}\right.$ $\mathrm{S} / \mathrm{cm})$ is dispersed into the PEO-based electrolyte, which enables the electrolyte a high ionic conductivity of $1.21 \times$ $10^{-3} \mathrm{~S} / \mathrm{cm}$ at $80^{\circ} \mathrm{C}$ (Zhao et al., 2016). Blanga et al. (2016) prepared a composite $\mathrm{Li}_{10} \mathrm{SnP}_{2} \mathrm{~S}_{12}$ (LSPS)/polyethylene oxide (PEO) electrolyte containing $25-50 \mathrm{wt} \%$ polymer which could 
act as a good barrier to suppress the shuttle of the polysulfide in Li-S battery. Meanwhile, a new composite $\mathrm{Li}_{10+\mathrm{x}} \mathrm{I}_{\mathrm{x}} \mathrm{SnP}_{2} \mathrm{~S}_{12}$ (LISPS)/P(EO) $3 /$ LiI solid electrolyte was formed by adding the saturated LiI salt and annealing at $90^{\circ} \mathrm{C}$. The solid electrolyte has an ionic conductivity of $0.1-0.3 \mathrm{mS} / \mathrm{cm}$ at room temperature, and the increase in polymer content or temperature can further improve the total ionic transport in the LISPS/PEO system (Figure 5A). Judez et al. (2017) studied a composite electrolyte of lithium bis(fluorosulfonyl)imide/poly(ethylene oxide) (LiFSI/PEO) containing lithium ion conductive glass ceramics (LICGC) and inorganic $\mathrm{Al}_{2} \mathrm{O}_{3}$ fillers. The CPE with $\mathrm{Al}_{2} \mathrm{O}_{3}$ filler improved the stability of the Li/electrolyte interface. The Li-S cells based on LICGC-based CPE provided a specific capacity of $1,111 \mathrm{mAh}$ g-1 and an area capacity of 1.14 $\mathrm{mAh} / \mathrm{cm}^{2}$. Fu et al. (2016) reported a 3D lithium ion-conductive ceramic network based on the garnet-type $\mathrm{Li}_{6.4} \mathrm{La}_{3} \mathrm{Zr}_{2} \mathrm{Al}_{0.2} \mathrm{O}_{12}$ (LLZO) lithium ion conductor, which provided a continuous $\mathrm{Li}^{+}$transmission channel in a polyethylene oxide (PEO) based composite (Figure 5B). While increasing the mechanical properties, the ionic conductivity is also improved, and the

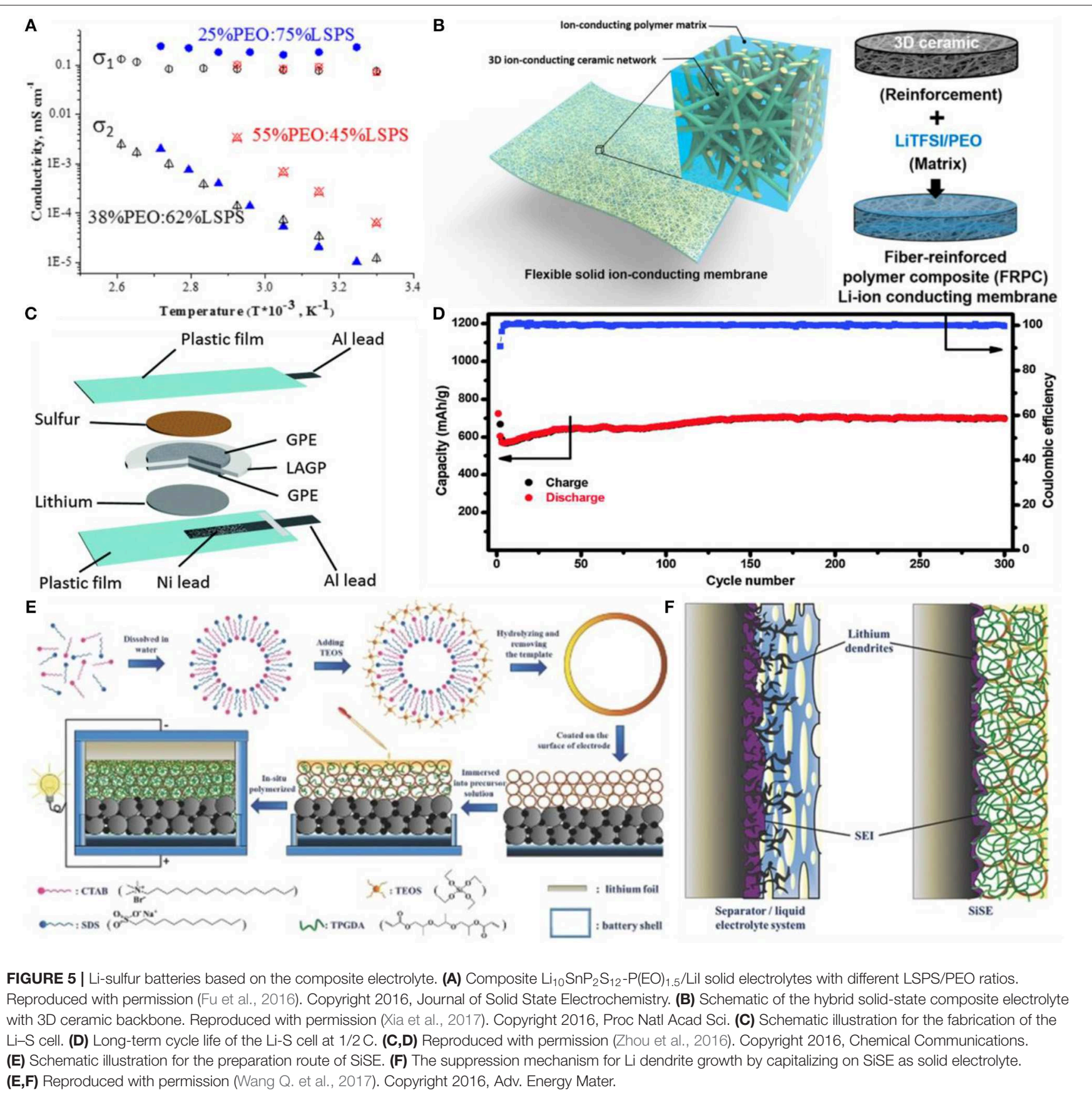


ionic conductivity at room temperature is $2.5 \times 10^{-4} \mathrm{~S} / \mathrm{cm}$. Wang Q. et al. (2016) newly designed a gel-ceramic multilayer electrolyte as shown in Figure 5C, which blocked the polysulfide shuttle, exhibiting excellent electrochemical performance and an initial discharge specific capacity up to $725 \mathrm{mAh} \mathrm{g}^{-1}$ with almost no self-discharge, and maintained $700 \mathrm{mAh} \mathrm{g}^{-1}$ after 300 cycles at C/2 (Figure 5D). Xia et al. (2017) prepared a PVDFHFP/LAGP composite electrolyte by adding the nano-fast ion conductor filler to the gel electrolyte, which had a high lithium ion migration number (0.51) and exhibited the electrochemical stability compared with the commercial liquid electrolyte. The solid lithium-sulfur battery assembled with the composite electrolyte showed an initial capacity of $918 \mathrm{mAh} \mathrm{g}^{-1}$ at $0.05 \mathrm{C}$, and good cycle performance. Zhou et al. (2016) fabricated a new $\mathrm{SiO}_{2}$ hollow nanosphere electrolyte (SiSE) by the adsorption and in situ polymerization of tripropylbenzodiacrylate (TPGDA) monomer with the addition of the $\mathrm{SiO}_{2}$ hollow nanosphere (Figure 5E). The silica layer not only enhanced the mechanical property of the electrolyte but also provided a high ionic conductivity $\left(1.74 \times 10^{-3} \mathrm{~S} / \mathrm{cm}\right)$ at room temperature, which effectively inhibited the growth of lithium dendrites (Figure 5F).

Although the polymer-inorganic composite electrolyte can effectively inhibit the shuttle of the polysulfide and control the growth of lithium dendrites to prevent the internal short circuit of the battery, the lithium ion conductivity is still too low, compared with the organic liquid-inorganic composite electrolyte at room temperature. The poor conductivity and migration number of the $\mathrm{Li}$ ions greatly limit the application of polymer-inorganic composite electrolytes. Wang et al. (2014) successfully realized the development and utilization of the organic liquid-inorganic composite electrolyte. When used in lithium-sulfur battery, the initial discharge specific capacity reached $1,528,1,386$, and $1,341 \mathrm{mAh} \mathrm{g}^{-1}$ at $\mathrm{C} / 20, \mathrm{C} / 5$, and $\mathrm{C} / 2$ rates, respectively, and remained $720 \mathrm{mAh} \mathrm{g}^{-1}$ after 40 cycles at $\mathrm{C} / 5$ rate. However, the researchers found that the active material is inevitably lost during the cycle process, resulting in a rapidly decline in capacity. In order to make full use of the active material and improve the cycle life, the group (Wang Q. et al., 2017) coated a carbon layer on the one side of the Li1.5Al0.5Ge1.5(PO4)3 (LAGP) facing the sulfur cathode. The innovative configuration not only improved the electron transport capacity of the sulfur-containing active material, but also improved the wettability of the ceramic electrolyte to the liquid electrolyte, thereby improving the cycle performance of the sulfur-containing active material. The interracially modified hybrid Li-S battery had an initial discharge capacity of 1,409 mAh $\mathrm{g}^{-1}$ and remained at $1,000 \mathrm{mAh} \mathrm{g}^{-1}$ after 50 cycles at a rate of $0.2 \mathrm{C}$.

All in all, the overall performance of the inorganic-organic composite electrolyte has been improved compared to the single all-solid polymer or inorganic electrolyte; stability, interfacial compatibility, safety and mechanical properties, and the ability of inhibiting the polysulfide shuttle have all improved. Therefore, it demonstrates great potential for use as an electrolyte for lithium-sulfur batteries, but the ionic conductivity at room temperature is still too low to meet the practical application.

\section{SULFUR CATHODE DESIGN FOR SOLID STATE LI-S BATTERIES}

For the sulfur cathode of the solid-state Li-S battery, the electrochemical reaction occurring in the "solid/solid/solid" three-phase boundary is more difficult to occur than "solid/liquid/solid" in the traditional liquid counterparts. Therefore, it is necessary to design the structure of the sulfur cathode elaborately and to develop the efficient preparation technology of the electrode to obtain the sulfur cathode with excellent ionic and electronic transport network. As well as that, it is necessary to maintain the relative stability of the electrode structure, eliminating the influence of volume expansion and contraction of the active material during discharge and charge cycles.

\section{Other Types of Sulfur Cathode}

Apart from choosing the elemental sulfur as the cathode material for Li-S batteries, the researchers have also studied the sulfide used as the cathode material instead of the sulfur. The common sulfides include the inorganic sulfides and the organic sulfides (Jing et al., 2017). The inorganic sulfides, such as FeS and CuS have an electronic conductivity of $2.1 \times 10^{-2} \mathrm{~S} / \mathrm{cm}$ (Zeng et al., 2014) and $10^{-3} \mathrm{~S} / \mathrm{cm}$, respectively (Lai et al., 2011). Table 2 summarizes the electrochemical performance of some inorganic sulfides as the positive electrode for the all-solid cells (Machida and Shigematsu, 2004; Machida et al., 2004; Kim et al., 2005; Hayashi et al., 2008; Sakuda et al., 2010; Tomonari et al., 2010; Aso et al., 2011; Lin et al., 2013a; Matsuyama et al., 2013; Chen M. et al., 2015; Long et al., 2016). The same in-situ growth method as the method used in fabricating the sulfur elemental positive electrode can also reduce the impedance of the interface and improve the cycle performance of the solid lithium-sulfur battery. Yao et al. (2016) fabricated the $\mathrm{CoS}_{2}-\mathrm{Li}_{7} \mathrm{P}_{3} \mathrm{~S}_{11}$ composite material using the in-situ liquid phase method fabricated (Figure 6A). The composite material maintained the nano-sheet structure of $\mathrm{CoS}_{2}$, and the $\mathrm{Li}_{7} \mathrm{P}_{3} \mathrm{~S}_{11}$ particles with the diameter of about $10 \mathrm{~nm}$ were distributed uniformly on the surface of the $\mathrm{CoS}_{2}$. The all solid-state lithium-sulfur battery was assembled with the $\operatorname{CoS}_{2}-\mathrm{Li}_{7} \mathrm{P}_{3} \mathrm{~S}_{11}$ composite material prepared with $\mathrm{w}\left(\mathrm{CoS}_{2}\right.$ $\left.\mathrm{Li}_{7} \mathrm{P}_{3} \mathrm{~S}_{11}\right): \mathrm{w}\left(\mathrm{Li}_{7} \mathrm{P}_{3} \mathrm{~S}_{11}\right): \mathrm{w}($ super $\mathrm{P})=4: 5: 1$ as the cathode, the $\mathrm{Li}_{7} \mathrm{P}_{3} \mathrm{~S}_{11}$ as the electrolyte, the lithium metal as the anode, exhibiting the specific capacity of $421 \mathrm{mAh} \mathrm{g}^{-1}$ at $1.27 \mathrm{~mA} / \mathrm{cm}$ at $25^{\circ} \mathrm{C}$ after 1,000 cycles. The $\mathrm{Li}_{2} \mathrm{~S}-\mathrm{Li}_{6} \mathrm{PS}_{5} \mathrm{Cl}-\mathrm{C}$ composite prepared by Han et al. (2016) (Figure 6B) exhibited an ionic conductivity of $10^{-5} \mathrm{~S} / \mathrm{cm}$ at room temperature at $50 \mathrm{~mA} \mathrm{~g}^{-1}$ and a high load of $\mathrm{Li}_{2} \mathrm{~S}\left(3.6 \mathrm{mg} \mathrm{cm}^{-2}\right)$ in the next 60 cycles also show a large reversible capacity of $830 \mathrm{mAh} \mathrm{g}^{-1}\left(\mathrm{Li}_{2} \mathrm{~S}\right.$ utilization reaches $71 \%$ ). Lin et al. (2013b) synthesized the $\mathrm{Li}_{3} \mathrm{PS}_{4}+\mathrm{n}$ with adding the $\mathrm{Li}_{3} \mathrm{PS}_{4}$ and $\mathrm{S}$ to the THF, showing the ionic conductivity of $3 \times$ $10^{-5} \mathrm{~S} / \mathrm{cm}$ at room temperature. The assembled all-solid lithiumsulfur battery showed the specific capacity of $600 \mathrm{mAh} \mathrm{g}^{-1}$ after 300 cycles at $0.1 \mathrm{C}$ at $60^{\circ} \mathrm{C}$.

Like the inorganic sulfide, the organic sulfide is also a research hotspot for Li-S battery. The sulfurized polyacrylonitrile is the most commonly used organic sulfide among the organic sulfide cathode materials. Yu et al. (2004) fabricated the cathode 
TABLE 2 | The electrochemical performance of inorganic sulfurized cathode in solid-state Li-sulfur battery.

\begin{tabular}{|c|c|c|c|c|c|c|c|}
\hline $\begin{array}{l}\text { Active } \\
\text { substance }\end{array}$ & Anode & Solid electrolyte & Cathode & $\begin{array}{l}\text { Current } \\
\text { density (mA } \\
\left.\mathrm{cm}^{-2}\right)\end{array}$ & $\begin{array}{l}\text { Specific } \\
\text { capacity } \\
\left(\mathrm{mAh} \mathrm{g}^{-1}\right)\end{array}$ & Cycles & References \\
\hline FeS & $w(\mathrm{FeS}): w(\mathrm{SE})=70: 30$ & $\mathrm{Li}_{3.25} \mathrm{Ge}_{0.25} \mathrm{P}_{0.75} \mathrm{~S}_{4}$ & Li-In & 0.191 & 430 & 15 & $\begin{array}{l}\text { Sakuda et al., } \\
2010\end{array}$ \\
\hline $\mathrm{Li}_{2} \mathrm{~S}-\mathrm{Cu}$ & $\begin{array}{l}w(C u): w(A B): w(S E)= \\
38: 5: 57\end{array}$ & $\left(\mathrm{Li}_{2} \mathrm{~S}\right)_{80}\left(\mathrm{P}_{2} \mathrm{~S}_{5}\right)_{20}$ & In & 0.64 & 60 & 50 & $\begin{array}{l}\text { Agostini et al., } \\
2013\end{array}$ \\
\hline $\mathrm{Li}_{2} \mathrm{~S}-\mathrm{C}$ & $\begin{array}{l}w\left(\mathrm{Li}_{2} \mathrm{~S}\right): \mathrm{w}(\mathrm{AB}): \mathrm{w}(\mathrm{SE})= \\
1.5: 1.5: 7\end{array}$ & $\mathrm{Li}_{3} \mathrm{PO}_{4}-\mathrm{Li}_{2} \mathrm{~S}-\mathrm{SiS}_{2}$ & In & 0.67 & 750 & 10 & Aso et al., 2011 \\
\hline $\mathrm{Li}_{2} \mathrm{~S}$ & $\begin{array}{l}w\left(\mathrm{Li}_{2} \mathrm{~S}\right): \mathrm{w}(\text { super } \mathrm{P}): \mathrm{w}(\mathrm{SE})= \\
35: 35: 30\end{array}$ & $\begin{array}{l}\mathrm{PEO}_{20} \mathrm{LiCF}_{3} \mathrm{SO}_{3}+10 \\
\mathrm{wt} \% \mathrm{~S}-\mathrm{ZrO}_{3}(\mathrm{EC} / \mathrm{DMC}: \mathrm{LiPF} \\
=6 \mathrm{~mol} / \mathrm{L})\end{array}$ & $\mathrm{Sn} / \mathrm{C}$ & 0.01 & 800 & 90 & $\begin{array}{l}\text { Matsuyama et al., } \\
2013\end{array}$ \\
\hline $\mathrm{TiS}_{3}$ & $\begin{array}{l}w\left(T \mathrm{TS}_{3}+\mathrm{S}\right): \mathrm{w}(\mathrm{AB}): \mathrm{w}(\mathrm{SE})= \\
40: 6: 54\end{array}$ & $\left(\mathrm{Li}_{2} \mathrm{~S}\right)_{80}\left(\mathrm{P}_{2} \mathrm{~S}_{5}\right)_{20}$ & $\mathrm{Li}-\mathrm{In}$ & 0.064 & 320 & 10 & $\begin{array}{l}\text { Chen M. et al., } \\
2015\end{array}$ \\
\hline $\mathrm{Li}_{3} \mathrm{PS}_{4} @ \mathrm{Li}_{2} \mathrm{~S}$ & $\begin{array}{l}w\left(\mathrm{Li}_{3} \mathrm{PS}_{4}\right): \mathrm{w}(\mathrm{C}): \mathrm{w}(\mathrm{PVC})= \\
65: 25: 10\end{array}$ & $\beta$-LiPS ${ }_{4}$ & $\mathrm{Li}-\mathrm{Ni}$ & 0.02 & 720 & 100 & Long et al., 2016 \\
\hline $\mathrm{MoS}_{2}$ & $\begin{array}{l}w\left(M_{0} S_{2}\right): w\left(L_{6} P_{5} B r\right): \\
w(\text { super } P)=40: 56: 4\end{array}$ & $\mathrm{Li}_{6} \mathrm{PS}_{5} \mathrm{Br}$ & Li-In & 0.04 & 270 & 100 & Yao et al., 2016 \\
\hline NiS & $\begin{array}{l}w(N i S): w(S E): w(A B)= \\
40: 50: 10\end{array}$ & $\begin{array}{l}\left(\mathrm{Li}_{2} \mathrm{~S}\right)_{70}\left(\mathrm{P}_{2} \mathrm{~S}_{5}\right)_{29} \mathrm{P}_{2} \mathrm{O}_{5} / \\
\mathrm{Li}_{10} \mathrm{GeP}_{2} \mathrm{~S}_{12}\end{array}$ & $\mathrm{Li}$ & 1.43 & 400 & 20 & Han et al., 2016 \\
\hline
\end{tabular}
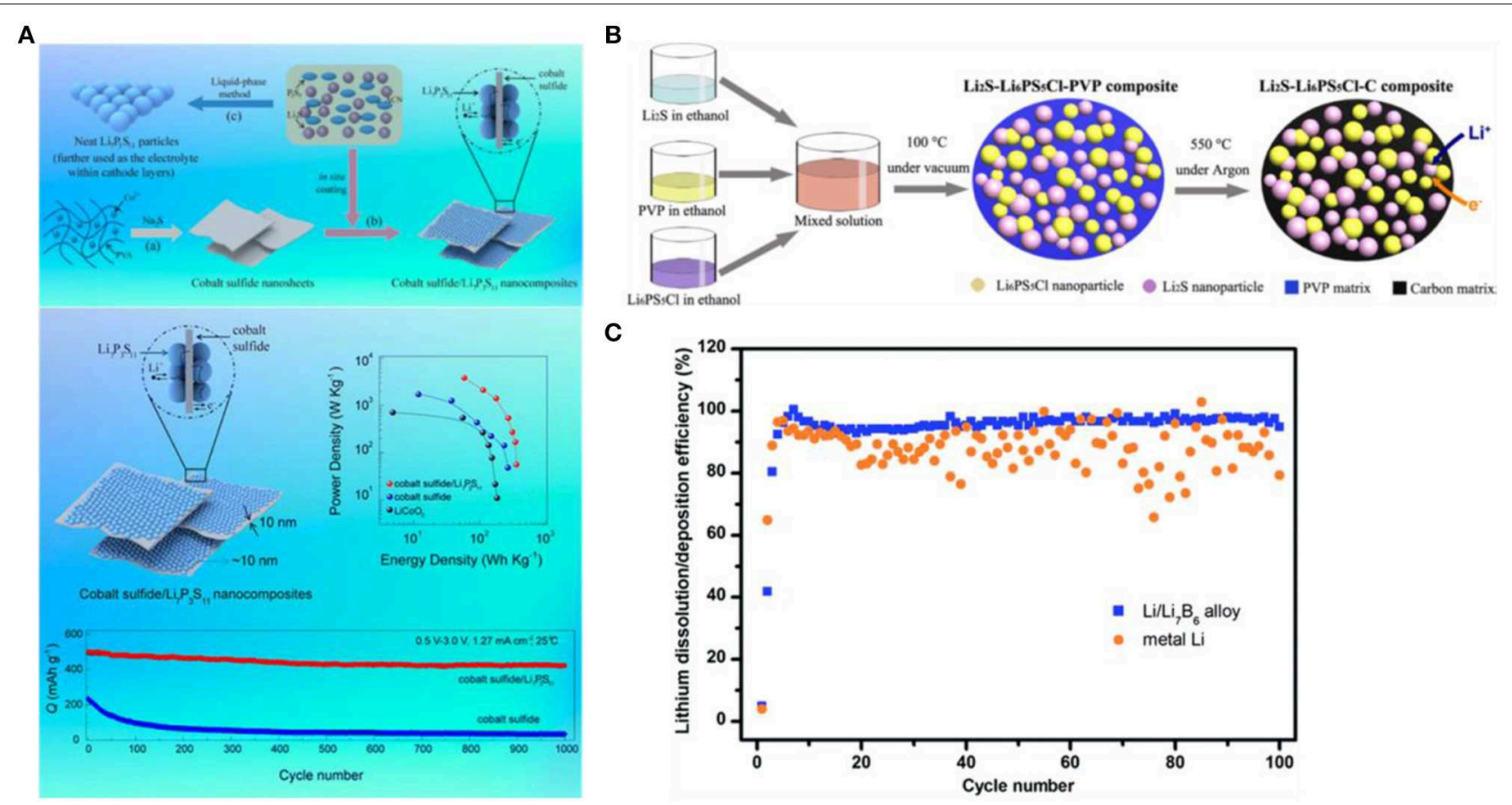

C

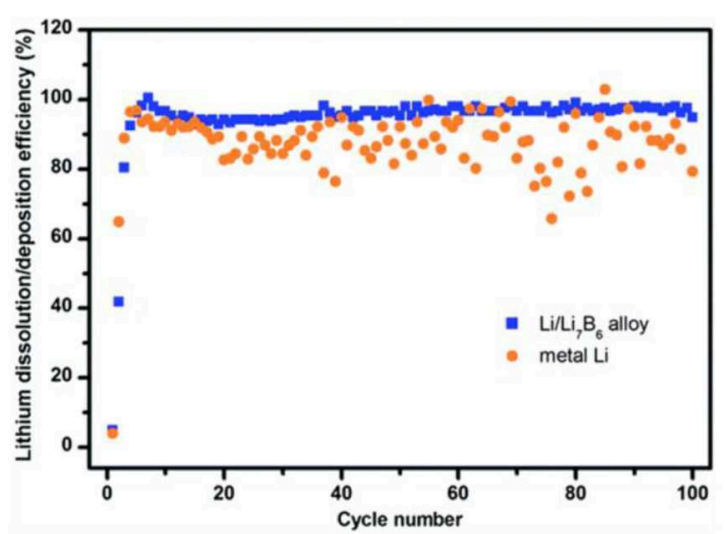

FIGURE 6 | Sulfur cathode and Lithium anode design for solide state Li-sulfur batteries. (A) Schematic illustration of the synthesis strategy for cobalt sulfide, cobalt sulfide-Li $\mathrm{L}_{3} \mathrm{P}_{31}$ nanocomposites, and neat $\mathrm{Li}_{7} \mathrm{P}_{3} \mathrm{~S}_{11}$ electrolyte. Reproduced with permission (Lin et al., 2013a). Copyright 2016, Nano Letters. (B) Schematic illustration of the bottom-up synthesis of the mixed conducting $\mathrm{Li}_{2} \mathrm{~S}$ nanocomposite. Reproduced with permission (Yu et al., 2004). Copyright 2016, Nano Letters. (C) Cycling efficiency of lithium deposition/dissolution for Li-B alloy (30 wt\% B) and metallic Li electrodes. Reproduced with permission (Bucur et al., 2016). Copyright 2014, Journal of Materials Chemistry A. 
materials using the sulfurized polyacrylonitrile as the active material of the positive electrode and a small amount of solid electrolyte and carbon black. The sulfur electrode was prepared by the mixing method, and the assembled all-solid lithiumsulfur battery was charged and discharged at a current density of $1 \mathrm{C}$ at $70^{\circ} \mathrm{C}$, which exhibited the specific capacity of 385 $\mathrm{mAh} \mathrm{g}^{-1}$ after 40 cycles. Zhang C. et al. (2015) assembled the all-solid lithium-sulfur battery with the PANI@C/S-280 as the cathode, the MIL-53 (Al) metal-organic framework modified solid electrolyte as the electrolyte, and the lithium metal as the anode. When charged and discharged at $0.2 \mathrm{C}$ at $80^{\circ} \mathrm{C}$, the battery showed a stable capacity of $876 \mathrm{mAh} \mathrm{g}^{-1}$. After 1,000 cycles at $80^{\circ} \mathrm{C}$, the battery exhibited the discharge capacity of 325 and $558 \mathrm{mAh} \mathrm{g}^{-1}$ at 2 and $1 \mathrm{C}$-rates, respectively. These results indicate that the combination of the PANI@C/S-280 cathode and the solid polymer electrolyte is an effective way to prevent the polysulfide dissolution and shuttle effect, thereby improving the performance of the battery.

\section{Add Conductive Agent and Binder}

When preparing the sulfur positive electrodes, the selection of the conductive agent is also an important issue to consider. The sulfur positive electrode was prepared by the ball milling with the conductive carbon black acetylene black (AB), the Ketjenblack $(\mathrm{KB})$ and the activated carbon (AC), and solid-state battery was assembled with solid electrolyte and Li-In alloy. It was found that the battery with $\mathrm{AB}$ as the conductive agent cannot be charged and discharged; the specific capacity of the battery, using $\mathrm{KB}$ and $\mathrm{AC}$ as the conductive agent at a current density of $0.64 \mathrm{~mA} \mathrm{~cm}^{-2}$, was about $1,600 \mathrm{mAh} \mathrm{g}^{-1}$; and the specific capacity of the electrode with $\mathrm{AC}$ as the conductive agent is higher than that using KB (Nagata and Chikusa, 2014a). This indicates that the conductive agent in the positive electrode can affect the electrochemical performance of the all-solid lithiumsulfur battery. Meanwhile, in order to further improve the contact between the sulfur positive electrode and the solid electrolyte, the sulfur and the porous carbon are generally prepared as a carbon-sulfur composite at high temperatures, and then mixed with the solid electrolyte. Liang et al. (2011b) prepared the carbon-sulfur composites (S-OMCs) with a sulfur content of $67 \%$ employing the carbon with a regular mesoporous structure as the carrier. An all-solid lithium-sulfur battery was assembled with a PEO-based solid electrolyte with the adding of $10 \%$ (mass fraction) of $\mathrm{SiO}_{2}$ inorganic filler, a metallic lithium negative electrode, and a sulfur-based positive electrode prepared on the basis of the carbon-sulfur composite. The battery was charged and discharged at a current density of $0.1 \mathrm{~mA} \mathrm{~cm}^{-1}$ at $70^{\circ} \mathrm{C}$, which exhibited the specific capacity of sulfur of $800 \mathrm{mAh} \mathrm{g}^{-1}$ after 25 cycles, and the capacity retention of $65 \%$. The sulfur positive electrode, which does not use the regular mesoporous carbon, has the capacity retention of only $22 \%$ after 25 cycles. Nagao et al. (2016) developed a carbon-sulfur composite using the mesoporous carbon with a pore diameter of $8.6 \mathrm{~nm}$ as the carrier, which showed a specific capacity of $366 \mathrm{mAh} \mathrm{g}^{-1}$ at a current density of $0.065 \mathrm{~mA} \mathrm{~cm}^{-2}$ and at room temperature after 20 cycles. When the mesoporous carbon with the pore diameter of 42.2 and $117.2 \mathrm{~nm}$ were used as the carriers, the specific capacities under the same conditions were 126 and $57 \mathrm{~mA} \mathrm{~h} \mathrm{~g}^{-1}(\mathrm{~S})$ after 20 cycles, respectively. In addition, many studies have shown that the temperature of the heat treatment of carbon-sulfur composites can also affect the electrochemical performance of the battery. For example, Nagao et al. (2013a) prepared a S-CMK3 composite cathode material with a sulfur content of $30 \%$ by the hot melt method. It was found that the temperature of the heat-treat of S-CMK3 increased from 170 to $230^{\circ} \mathrm{C}$, and it was still reversible after 30 cycles under the same condition. The specific capacity was increased from $500 \mathrm{~mA} \cdot \mathrm{h}$ $\mathrm{g}^{-1}(\mathrm{~S})$ to $1,300 \mathrm{~mA} \cdot \mathrm{h} / \mathrm{g}(\mathrm{S})$. The result of the XRD test shows that (Nagao et al., 2013b), after heating to $230^{\circ} \mathrm{C}$, the sulfur randomly disperses on the inner wall of CMK3, which improves the electrochemical performance and the cycle stability.

As described above, the electronic conductivity of $S$ and lithiated S species is poor, and various conductive polymers are used as binders to overcome this limitation. In addition to the problem of electronic conductivity, the intermediate product $\mathrm{Li}_{2} \mathrm{~S}_{\mathrm{x}}(2<\mathrm{x}<8)$ can be dissolved in a common organic electrolyte. To prevent this dissolution that can lead to selfdischarge, inefficiency, and poor cycle stability, the researchers designed adhesives and conductive carbon additives to capture polysulfides through precise chemical reactions (Pang et al., 2016; Hao et al., 2018). Strong coordination between polar functional groups containing $\mathrm{N}, \mathrm{O}$ or $\mathrm{S}$ in the polymer binder, resulting in an interaction strength of $\sim 1-2 \mathrm{eV}$ with $\mathrm{Li}_{2} \mathrm{~S}_{\mathrm{x}}$, while $\mathrm{Li}-\mathrm{X}(\mathrm{X}=$ $\mathrm{N}, \mathrm{O}, \mathrm{S}$ or Other types) are stronger, which increases the retention of polysulfide (Li et al., 2013; Seh et al., 2013; Ma et al., 2014; Park et al., 2015). Due to the strong ionic character of polysulfide species, positively charged polyelectrolyte material is used as a binder to trap $S_{x}^{2-}$ (Bucur et al., 2016; Li L. et al., 2017) and a negatively charged polymer is coated on the separator to Repel multi-sulfide to prevent crossover.

\section{Interface Contact and Sulfur Cathode Preparation}

While optimizing the sulfur positive electrode, the interface contact between the electrode and the solid electrolyte should also be considered. For the all-solid lithium-sulfur battery, the poor contact between the solid/solid interface enables a large interfacial impedance, which greatly decreases the cycle performance of the battery. The preparation of the sulfur cathode in lithium-sulfur batteries is crucial to achieve the high performance. At present, the preparation method of the sulfur positive electrode of the solid lithium-sulfur battery is mainly the physical mixing method (such as grinding, ball milling, etc.), heat treatment method and the like. For example, Zhu et al. (2005) prepared a sulfur positive electrode with w (single sulfur): $\mathrm{w}(\mathrm{PEO})=3: 7$ by ball milling and heat treatment at $180^{\circ} \mathrm{C}$ in an inert atmosphere. The prepared sulfur positive electrode was assembled into an all-solid lithium-sulfur battery with a $\mathrm{P}(\mathrm{EO}) 20 \mathrm{LiTFSI}-10 \mathrm{wt} \% \gamma$-LiAlO2 solid electrolyte and a metallic lithium anode. At room temperature, the first discharge specific capacity of the sulfur positive electrode using the ball milling process was $609 \mathrm{mAh}$ g-1, which was higher than the sulfur positive electrode using the heat treatment process. Kinoshita 
et al. (2014) prepared the positive electrode with $\mathrm{w}$ (single sulfur): $w$ (carbon fiber): $w$ (Li3PS4) $=3: 1: 6$ via a two-step ball milling method, wherein the sulfur loading was $4.29 \mathrm{mg}$ $\mathrm{cm}^{-2}$, the initial specific capacity was $1,320 \mathrm{mAh} \mathrm{g}^{-1}$ at a current density of $0.1 \mathrm{~mA} \mathrm{~cm}^{-2}$ at $25^{\circ} \mathrm{C}$. The average operating voltage of the battery was $1.5 \mathrm{~V}$ and the capacity retention after 50 cycles was $90 \%$. Further studies have shown that the conductivity of the solid electrolyte in the positive electrode is not the only factor affecting the electrochemical performance of the battery. For example, Nagata and Chikusa (2014b), Nagata and Chikusa (2014c) compared the effect of $\mathrm{Li}_{2} \mathrm{~S}-\mathrm{P}_{2} \mathrm{~S}_{5}$ solid electrolyte with different phosphorus-to-sulfur ratio $(\mathrm{P} / \mathrm{S})$ on the electrochemical performance of the battery. As the $\mathrm{P} / \mathrm{S}$ value of the solid electrolyte in the electrode increases, the specific capacity of sulfur increases first,and then decreases to $7 \%$.

The in-situ growth method can be used to decrease the impedance of the "solid/solid/solid" three-phase interface and improve the compatibility of the interface. The in-situ growth technique can effectively improve the contact between the solid electrolyte and the electrode, facilitate the rapid transfer of lithium ions, and improve the rate performance and cycle life, thereby improving the electrochemical performance. Nagata and Chikusa (2014b) assembled the solid battery with the sulfur positive electrode prepared by the ball milling method, and the solid electrolyte $\mathrm{Li}_{10} \mathrm{GeP}_{2} \mathrm{~S}_{12}$ prepared by the constant current and constant pressure electrolysis method in situ in a pole piece and with the lithium indium alloy ( $\mathrm{Li}-\mathrm{In}$ ) negative electrode. The battery charged and discharged at a current density of $1.6 \mathrm{~mA}$ $\mathrm{cm}^{-2}$ at $25^{\circ} \mathrm{C}$ exhibited the specific capacity of $1,200 \mathrm{mAh} \mathrm{g}^{-1}$ after 10 cycles.

In summary, in order to improve the "solid/solid/solid" threephase interface problem, a series of studies have been conducted on the sulfur positive electrode. From the loading of the sulfur element to the design and preparation of the sulfur positive electrode, these improvements have greatly improved the cycle performance of the solid lithium-sulfur battery. But for the purpose of reducing impedance, the in-situ growth of the positive electrode is performed to reduce impedance. In-situ synthesis can effectively improve the contact between interfaces. On the one hand, in-situ synthesis can simplify the process and facilitate the modification of the interface. On the other hand, through the analysis of the microstructure, it can be concluded that the in-situ synthesis enables the interface compatible. In addition, the interface can be constructed by adding a small molecule polymer and coating a small liquid molecule on the surface of the sulfur positive electrode to completely infiltrate the sulfur positive electrode, and polymerizing the small molecule through an initiator to improve the interface compatibility.

\section{STABLE LITHIUM ANODE FOR SOLID STATE Li-S BATTERIES}

The use of lithium alloy can reduce the reducibility and activity of the metallic lithium. The Lithium alloy negative electrodes for allsolid lithium-sulfur batteries reported in the literature are mainly
Li-In, Li-Ge, Li-Si and Li-Al. Among them, Li-In alloy (Li/In = 0.79 , molar ratio) is the most widely used, and its redox potential is $+0.6 \mathrm{~V}\left(\mathrm{Li}^{+} / \mathrm{Li}\right.$ ) (Wen and Huggins, 1980). Nagata and Chikusa (2014a) used the Li-In alloy as the negative electrode, and the sulfide $\mathrm{Li}_{10} \mathrm{GeP}_{2} \mathrm{~S}_{12}$ as the solid electrolyte assembling the all-solid Li-S battery. The charge and discharge were performed at a current density of $1 \mathrm{C}$, and the specific capacity was about $1,600 \mathrm{mAh}_{(\mathrm{S})}^{-1}$, and the capacity retention was closed to $100 \%$. Zhang X. et al. (2014) used the Li-B alloy as the negative electrode and formed a passivation film on the negative electrode, which effectively reduced the performance loss caused by the volume change of the alloy. The battery assembled with the Li-B alloy has a very stable cycle performance as shown in Figure 6C.

Nagao et al. (2012) deposited a lithium film by vacuum evaporation to increase the contact area between the lithium electrode and the $\mathrm{Li}_{2} \mathrm{~S}-\mathrm{P}_{2} \mathrm{~S}_{5}$ solid electrolyte. The effect of the insertion of lithium film on the reversibility of lithium dissolution and the deposition of all solid-state cells were also investigated. The electrochemical test showed that the charge and discharge were performed at a current density of $0.064 \mathrm{~mA} \mathrm{~cm}^{-2}$, and

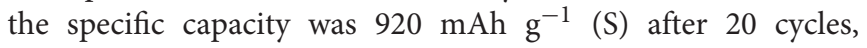
and the capacity retention was $97 \%$. Wang et al. (2013) added a gel polymer electrolyte and a ceramic film on the surface of the lithium negative electrode. The ceramic film is a solid film of $\mathrm{Li}_{2} \mathrm{O}-\mathrm{Al}_{2} \mathrm{O}_{3}-\mathrm{SiO}_{2}-\mathrm{P}_{2} \mathrm{O}_{5}-\mathrm{TiO}_{2}-\mathrm{GeO}_{2}$, which prevents the direct contact between the lithium negative electrode and the electrolyte, making the interface contact more compacter, decreasing the interfacial impedance, and greatly enabling the batter cycle performance. The energy density can reach $446 \mathrm{Wh}$ $\mathrm{kg}^{-1}$, which is about $80 \%$ higher than the traditional lithiumion batteries, and its power efficiency can reach more than $95 \%$. Han et al. (2017) demonstrated that the large interfacial resistance came from the physical and/or chemical instability between the solid electrolytes and the metallic $\mathrm{Li}$. Hu et al. showed a strategy to deposit the ultrathin intermediates [such as alumina $\left(\mathrm{Al}_{2} \mathrm{O}_{3}\right)$, zinc oxide $(\mathrm{ZnO})$, germanium $(\mathrm{Ge})$, silicon $(\mathrm{Si})$, metal aluminum (Al)] on Garnets, forming a continuous and conformal interface [lithium aluminum, Li Zn alloy (Wang C. et al., 2017), Li Ge alloy (Luo et al., 2017), Li Si alloy (Kim et al., 2014), Li Al alloy (Fu et al., 2017b)], which can enhance the surface wettability of the stone toward Li metal. Compared to the pure LLZO particles, the LLZO coating with $\mathrm{Al}_{2} \mathrm{O}_{3}$ prepared by the atomic layer deposition (ALD) exhibits a much smaller interfacial impedance of $1 \Omega \mathrm{cm}^{-2}$. The similar observations have been observed in the work of Ge-coated garnet and Al-coated garnet systems. The aluminum-coated garnet hybrid SSE system effectively prevented the migration/shuttle effect of LiPSs and successfully solved the wetting problem between the Garnet SSE and the Lithium metal (Fu et al., 2017b). It is worth noting that the layer formed in situ by chemical reaction is critical to improving the stability between the Li metal anode and the SSE. Hood et al. (2016) reported a self-limiting interfacial reaction between the $\mathrm{Li}_{2} \mathrm{OHCl}$ solid electrolyte and the Li-metal anode to form an extremely stable interface. The $\mathrm{Li} / \mathrm{Li}_{2} \mathrm{OHCl} / \mathrm{Li}$ battery circulated at $195^{\circ} \mathrm{C}$ showed that the stability between the solid electrolyte and the molten $\mathrm{Li}$ anode was achieved during the formation of the SEI, in which the 
interfacial resistance between the $\mathrm{Li}_{2} \mathrm{OHCl}$ solid electrolyte and the Li metal was small.

In summary, the metallic lithium has strong reducibility, and it is necessary to study the interfacial compatibility of the lithium metal with the solid electrolyte, establish an interface modification method, and develop a metal lithium negative electrode with a highly stable three-dimensional structure.

\section{SUMMARY AND OUTLOOK}

This review summarizes the concept and preparation technologies for solid-state Li-S batteries in recent years. The recent research progress on different kinds of solid-state electrolytes and their specific mechanical, charge transfer and chemical properties were discussed in detail, as well as the advantages and disadvantages of the solid-state electrolyte. The selection of the solid-state electrolyte and how to stabilize the solid/solid/solid three-phase interface both hold the key to the success of solid Li-sulfur batteries. As well, the technical challenges of solid-state lithium-sulfur batteries are also systematically described in the design and preparation of sulfur positive electrode and lithium negative electrode.

The stand out challenges facing the solid-state electrolyte materials includes the development of the fast lithium ion transport at room temperature, the establishment of a highquality electrode/electrolyte architecture to improve the "solid/solid/solid" three-phase contact, the further stabilization

\section{REFERENCES}

Abraham, K. M., and Alamgir, M. (1991). Dimensionally stable MEEP-based polymer electrolytes and solid-state lithium batteries. Chem. Mater. 3, 339-348. doi: $10.1021 / \mathrm{cm} 00014 \mathrm{a} 027$

Agostini, M., Aihara, Y., Yamada, T., Scrosati, B., and Hassoun, J. (2013). A lithium-sulfur battery using a solid, glass-type P2S5-Li2S electrolyte. Solid State Ionics 244, 48-51. doi: 10.1016/j.ssi.2013.04.024

Agostini, M., and Hassoun, J. (2015). A lithium-ion sulfur battery using a polymer, polysulfide-added membrane. Sci. Rep. 5:7591. doi: 10.1038/srep07591

Agostini, M., Lim, D. H., Sadd, M., Fasciani, C., Navarra, M. A., Panero, S., et al. (2017). Stabilizing the performance of high-capacity sulfur composite electrodes by a new gel polymer electrolyte configuration. ChemSusChem 10:1700977. doi: 10.1002/cssc.201700977

Agrawal, R. C., and Pandey, G. P. (2008). Solid polymer electrolytes: materials designing and all-solid-state battery applications: an overview. J. Phys. D Appl. Phys. 41:22. doi: 10.1088/0022-3727/41/22/223001

Arbi, K., Rojo, J. M., and Sanz, J. (2007). Lithium mobility in titanium based Nasicon $\mathrm{Li}_{1+x} \mathrm{Ti}_{2}-\mathrm{xAl} x\left(\mathrm{PO}_{4}\right)_{3}$ and $\mathrm{LiTi}_{2}-\mathrm{x} \mathrm{Zr}_{x}\left(\mathrm{PO}_{4}\right)_{3}$ materials followed by NMR and impedance spectroscopy. J. Eur. Ceram. Soc. 27, 4215-4218. doi: 10.1016/j.jeurceramsoc.2007.02.118

Arumugam, M. Y., Sheng-Heng, F., Chenxi, C., and Yu-Sheng, Z. (2014). Rechargeable lithium-sulfur batteries. Chem. Rev. 114, 11751-11787. doi: $10.1021 / \mathrm{cr} 500062 \mathrm{v}$

Aso, K., Hayashi, A., and Tatsumisago, M. (2011). Synthesis of needlelike and platelike sns active materials in high-boiling solvents and their application to all-solid-state lithium secondary batteries. Crystal Growth Design 11, 3900-3904. doi: 10.1021/cg200459t

Baloch, M., Vizintin, A., Chellappan, R. K., Moskon, J., Shanmukaraj, D., Dedryvere, R., et al. (2016). Application of gel polymer electrolytes based on ionic liquids in lithium-sulfur batteries. J. Electrochem. Soc. 163, A2390-A2398. doi: $10.1149 / 2.1151610$ jes of high-capacity electrodes. Prospective approaches to solving these problems can draw inspiration from the latest trends in polymer science, including the use of highly specific sequence control to obtain well-defined structures, the use of secondary structural modifications to extend control over material properties, and the materials with recyclable chemical design or bio-inspired molecular structures.

In short, all-solid lithium-sulfur batteries will play a pivotal role in the successful deployment of clean energy and achieve carbon neutral society, and the development prospects are worth looking forward to.

\section{AUTHOR CONTRIBUTIONS}

All authors listed have made a substantial, direct and intellectual contribution to the work, and approved it for publication.

\section{FUNDING}

This work was supported by the National Natural Science Foundation of China (21771018, 21875004), Beijing University of Chemical Technology (start-up grant buctrc201901, BUCT, China), the Program for Changjiang Scholars and Innovative Research Team in the University, the Fundamental Research Funds for the Central Universities, and the Long Term Subsidy Mechanism from the Ministry of Finance and the Ministry of Education of PRC.

Barchasz, C., Leprêtre, J. C., Alloin, F., and Patoux, S. (2012). New insights into the limiting parameters of the Li/S rechargeable cell. J. Power Sources 199, 322-330. doi: 10.1016/j.jpowsour.2011.07.021

Ben Youcef, H., Garcia-Calvo, O., Lago, N., Devaraj, S., and Armand, M. (2016). Cross-linked solid polymer electrolyte for all-solid-state rechargeable lithium batteries. Electrochim. Acta 220, 587-594. doi: 10.1016/j.electacta.2016. 10.122

Blanga, R., Goor, M., Burstein, L., Gladkich, A., Logvinuk, D., Shechtman, I., et al. (2016). The search for a solid electrolyte, as a polysulfide barrier, for lithium/sulfur batteries. J. Solid State Electrochem. 20, 3393-3404. doi: 10.1007/s10008-016-3303-7

Bohnke, O. (2008). The fast lithium-ion conducting oxides $\mathrm{Li}_{3 x} \mathrm{La}_{2 / 3}$ ${ }_{x} \mathrm{TiO}_{3}$ from fundamentals to application. Solid State Ionics 179, 9-15. doi: 10.1016/j.ssi.2007.12.022

Bronstein, L. M., Karlinsey, R. L., Ritter, K., Joo, C. G., Stein, B., and Zwanziger, J. W. (2004). Design of organic-inorganic solid polymer electrolytes: synthesis, structure, and properties. J. Mater. Chem. 14, 1812-1820. doi: 10.1039/B401826E

Bruce, P. G., Freunberger, S. A., Hardwick, L. J., and Tarascon, J. M. (2011). Li-O $\mathrm{O}_{2}$ and Li-S batteries with high energy storage. Nat. Mater. 11, 19-29. doi: $10.1038 /$ nmat3191

Bucur, C. B., Muldoon, J., and Lita, A. (2016). A layer-by-layer supramolecular structure for a sulfur cathode. Energy and Environ. Sci. 9, 992-998. doi: 10.1039/C5EE02367J

Cao, R., Xu, W., Lv, D.,Xiao, J., and Zhang, J. G. (2015). Anodes for rechargeable lithium-sulfur batteries. Adv. Energy Mater. 5:1402273. doi: 10.1002/aenm.201402273

Capuano, F. (1991). Composite polymer electrolytes. J. Electrochem. Soc. 138:1918. doi: 10.1149/1.2085900

Chen, M., Yin, X., Reddy, M. V., and Adams, S. (2015). All-solid-state $\mathrm{MoS}_{2} / \mathrm{Li}_{6} \mathrm{PS} 5 \mathrm{Br} / \mathrm{In}-\mathrm{Li}$ batteries as a novel type of Li/S battery. J. Mater. Chem. A 3, 10698-10702. doi: 10.1039/C5TA02372F 
Chen, R., Qu, W., Guo, X., Li, L., and Wu, F. (2016). The pursuit of solidstate electrolytes for lithium batteries: from comprehensive insight to emerging horizons. Materials Horizons 3, 487-516. doi: 10.1039/C6MH00218H

Chen, R., Zhao, T., and Wu, F. (2015). From a historic review to horizons beyond: lithium-sulphur batteries run on the wheels. Chem. Commun. 51, 18-33. doi: $10.1039 /$ c4cc05109b

Chen, W., Lei, T., Wu, C., Deng, M., Gong, C., Hu, K., et al. (2018). Designing safe electrolyte systems for a high-stability lithium-sulfur battery. Adv. Energy Mater. 8:1702348. doi: 10.1002/aenm.201702348

Cheng, X. B., Zhang, R., Zhao, C. Z., Wei, F., Zhang, J. G., and Zhang, Q. (2016). A review of solid electrolyte interphases on lithium metal anode. Adv. Sci. 3:1500213. doi: 10.1002/advs.201500213

Cheng, X. B., Zhang, R., Zhao, C. Z., and Zhang, Q. (2017). Toward safe lithium metal anode in rechargeable batteries: a review. Chem. Rev. 15, 10403-10473. doi: 10.1021/acs.chemrev.7b00115

Cheng, Y., Zhang, L., Xu, S., Zhang, H., Ren, B., Li, T., et al. (2018). Ionic liquid functionalized electrospun gel polymer electrolyte for use in a highperformance lithium metal battery. J. Mater. Chem. A 6, 18479-18487. doi: 10.1039/C8TA06338A

Choe, H. S., Giaccai, J., Alamgir, M., and Abraham, K. M. (1995). Preparation and characterization of poly(vinyl sulfone)- and poly(vinylidene fluoride)-based electrolytes. Electrochim. Acta 40, 2289-2293. doi: 10.1016/0013-4686(95)00180-M

Choi, J. H., Lee, C. H., Yu, J. H., Doh, C. H., and Lee, S. M. (2015). Enhancement of ionic conductivity of composite membranes for allsolid-state lithium rechargeable batteries incorporating tetragonal $\mathrm{Li}_{7} \mathrm{La}_{3} \mathrm{Zr}_{2} \mathrm{O}_{12}$ into a polyethylene oxide matrix. J. Power Sources 274, 458-463. doi: 10.1016/j.jpowsour.2014.10.078

Choi, S., Song, J., Wang, C., Park, S., and Wang, G. (2017). Multifunctional free-standing gel polymer electrolyte with carbon nanofiber interlayers for high-performance lithium-sulfur batteries. Chem. Asian J. 12, 1470-1474. doi: 10.1002/asia.201700402

Choudhury, S., Saha, T., Naskar, K., Stamm, M., Heinrich, G., and Das, A. (2017). A highly stretchable gel-polymer electrolyte for lithium-sulfur batteries. Polymer112, 447-456. doi: 10.1016/j.polymer.2017.02.021

Croce, F., Appetecchi, G. B., Persi, L., and Scrosati, B. (1998). Nanocomposite polymer electrolytes for lithium batteries. Nature 394, 456-458. doi: $10.1038 / 28818$

Fu, K. K., Gong, Y., Dai, J., Gong, A., Han, X., Yao, Y., et al. (2016). Flexible, solid-state, ion-conducting membrane with 3D garnet nanofiber networks for lithium batteries. Proc. Natl. Acad. Sci. U.S.A. 113, 7094-7099. doi: 10.1073/pnas.1600422113

Fu, K. K., Gong, Y., Hitz, G. T., McOwen, D. W., Li, Y., Xu, S., et al. (2017a). Three-dimensional bilayer garnet solid electrolyte based high energy density lithium metal-sulfur batteries. Energy Environ. Sci. 10, 1568-1575. doi: 10.1039/C7EE01004D

Fu, K. K., Gong, Y., Liu, B., Zhu, Y., Xu, S., Yao, Y., et al. (2017b). Toward garnet electrolyte-based Li metal batteries: an ultrathin, highly effective, artificial solidstate electrolyte/metallic Li interface. Sci. Adv. 3:4. doi: 10.1126/sciadv.1601659

Gao, S., Wang, K., Wang, R., Jiang, M., Han, J., Gu, T., et al. (2017). Poly(vinylidene fluoride)-based hybrid gel polymer electrolytes for additive-free lithium sulfur batteries. J. Mater. Chem. A 5, 17889-17895. doi: 10.1039/C7TA0 $5145 \mathrm{~J}$

Goodenough, J. B., and Kim, Y. (2010). Challenges for rechargeable li batteries ${ }^{\dagger}$. Chem. Mater. 22, 587-603. doi: 10.1021/cm901452z

Han, F., Yue, J., Fan, X., Gao, T., Luo, C., Ma, Z., et al. (2016). High-performance all-solid-state lithium-sulfur battery enabled by a mixed-conductive Li2S nanocomposite. Nano Lett. 16, 4521-4527. doi: 10.1021/acs.nanolett.6b01754

Han, X., Gong, Y., Fu, K. K., He, X., Hitz, G. T., Dai, J., et al. (2017). Negating interfacial impedance in garnet-based solid-state Li metal batteries. Nat. Mater. 16, 572-579. doi: $10.1038 /$ nmat4821

Hancock, K., Becherer, J., Hagen, M., Joos, M., Abert, M., Mueller, D., et al. (2018). Electrolyte decomposition and electrode thickness changes in Li-S cells with lithium metal anodes, prelithiated silicon anodes and hard carbon anodes. J. Electrochem. Soc. 165, A6091-A6106. doi: 10.1149/2.0161801jes

Hao, C., Min, L., Luke, H., Han, Y. L., Gaoran, L., Zhan, L., et al. (2018). Exploring chemical, mechanical, and electrical functionalities of binders for advanced energy-storage devices. Chem. Rev. 118, 8936-8982 doi: 10.1021/acs.chemrev.8b00241

Hassoun, J., and Scrosati, B. (2010). Moving to a solid-state configuration: a valid approach to making lithium-sulfur batteries viable for practical applications. Adv. Mater. Weinheim. 22, 5198-5201. doi: 10.1002/adma.201002584

Hayashi, A., Ohtomo, T., Mizuno, F., Tadanaga, K., and Tatsumisago, M. (2003). All-solid-state Li/S batteries with highly conductive glass-ceramic electrolytes. Electrochem. Commun. 5, 701-705. doi: 10.1016/S1388-2481(03)00167-X

Hayashi, A., Ohtsubo, R., Ohtomo, T., Mizuno, F., and Tatsumisago, M. (2008). All-solid-state rechargeable lithium batteries with Li2S as a positive electrode material. J. Power Sources 183, 422-426. doi: 10.1016/j.jpowsour.2008.05.031

Ho Park, J., Yeo, S. Y., Park, J. K., and Lee, Y. M. (2010). Electrochemical performance of lithium sulfur batteries with plasticized polymer electrolytes based on $\mathrm{P}(\mathrm{VdF}-\mathrm{co}-\mathrm{HFP})$. J. Korean Electrochem. So 13, 110-115. doi: 10.5229/JKES.2010.13.2.110

Hood, Z. D., Wang, H., Samuthira Pandian, A., Keum, J. K., and Liang, C. (2016). $\mathrm{Li}_{2} \mathrm{OHCl}$ crystalline electrolyte for stable metallic lithium anodes. J. Am. Chem. Soc. 138, 1768-1771. doi: 10.1021/jacs.5b11851

Hovington, P., Lagacé, M., Guerfi, A., Bouchard, P., Mauger, A., Julien, C. M., et al. (2015). New lithium metal polymer solid state battery for an ultrahigh energy: nano C-LiFePO4 versus nano Li1.2V3O8. Nano Lett. 15, 2671-2678. doi: 10.1021/acs.nanolett.5b00326

Jeddi, K., Sarikhani, K., Qazvini, N. T., and Chen, P. (2014). Stabilizing lithium/sulfur batteries by a composite polymer electrolyte containing mesoporous silica particles. J. Power Sources 245, 656-662. doi: 10.1016/j.jpowsour.2013.06.147

Jeong, S. S., Lim, Y. T., Choi, Y. J., Cho, G. B., Kim, K. W., Ahn, H. J., et al. (2007). Electrochemical properties of lithium sulfur cells using PEO polymer electrolytes prepared under three different mixing conditions. J. Power Sources 174, 745-750. doi: 10.1016/j.jpowsour.2007.06.108

Jeong, S. S., Lim, Y. T., Jung, B. S., and Kim, K. W. (2005). "Electrochemical characteristics of $\mathrm{Li} / \mathrm{S}$ secondary battery with $(\mathrm{PEO})(6) \mathrm{LiBF}_{4}-\mathrm{Al}_{2} \mathrm{O}_{3}$ composite polymer electrolyte prepared by ball milling, in Eco-Materials Processing \& Design Vi, Vol. 486-487, eds H. S. Kim, S. Y. Park, B. Y. Hur, 594-597. doi: 10.4028/0-87849-966-0.594

Jiaqiang, E., Jin, Y., Deng, Y., Zhao, X., Han, D., Peng, Q., et al. (2017). Wetting models and working mechanisms of typical surfaces existing in nature and their application on superhydrophobic surfaces: a review. Adv. Mater. Interfaces 2017:1701052. doi: 10.1002/admi.201701052

Jin, J., Wen, Z., Liang, X., Cui, Y., and Wu, X. (2012). Gel polymer electrolyte with ionic liquid for high performance lithium sulfur battery. Solid State Ionics Diffus. React. 225, 604-607. doi: 10.1016/j.ssi.2012.03.012

Jing, G., Wenfeng, R., and Jian, C. (2017). Research progress of allsolid lithium-sulfur battery. Energy Storage Sci.Technol. 2, 199-230. doi: 10.1007/s41918-019-00029-3

Jozwiuk, A., Berkes, B. B., Weiss, T., Sommer, H., Janek, J., and Brezesinski, T. (2016). The critical role of lithium nitrate in the gas evolution of lithium-sulfur batteries. Energy Environ. Sci. 9, 2603-2608. doi: 10.1039/C6EE00789A

Judez, X., Zhang, H., Li, C., Eshetu, G. G., Zhang, Y., González-Marcos, J. A., et al. (2017). Polymer-rich composite electrolytes for all-solid-state Li-S cells. J. Phys. Chem. Lett. 8, 3473-3477. doi: 10.1021/acs.jpclett.7b01321

Kamyshny, A., Gun, J., Rizkov, D., Voitsekovski, T., and Lev, O. (2007). Equilibrium distribution of polysulfide ions in aqueous solutions at different temperatures by rapid single phase derivatization. Environ. Sci. Technol. 41, 2395-2400. doi: 10.1021/es062637+

Kato, Y., Hori, S., Saito, T., Suzuki, K., Hirayama, M., Mitsui, A., et al. (2016). Highpower all-solid-state batteries using sulfide superionic conductors. Nat. Energy 1:16030. doi: 10.1038/nenergy.2016.30

Kim, B. C., Takada, K., Ohta, N., Seino, Y., Zhang, L., Wada, H., et al. (2005). All solid state Li-ion secondary battery with FeS anode. Solid State Ionics, Diffusion and Reactions, 176, 2383-2387. doi: 10.1016/j.ssi.2005.05.019

Kim, J.-K. (2017). Hybrid gel polymer electrolyte for high-safety lithium-sulfur batteries. Mater. Lett. 187, 40-43. doi: 10.1016/j.matlet.2016.10.069

Kim, K. M., Poliquit, B. Z., Lee, Y.-G., Won, J., Ko, J. M., and Cho, W. I. (2014). Enhanced separator properties by thermal curing of poly(ethylene glycol)diacrylate-based gel polymer electrolytes for lithium-ion batteries. Electrochim. Acta 120, 159-166. doi: 10.1016/j.electacta.2013.12.077 
Kinoshita, S., Okuda, K., Machida, N., Naito, M., and Sigematsu, T. (2014). All-solid-state lithium battery with sulfur/carbon composites as positive electrode materials. Solid State Ionics 256, 97-102. doi: 10.1016/j.ssi.2013. 12.045

Kobayashi, T., Imade, Y., Shishihara, D., Homma, K., Nagao, M., Watanabe, R., et al. (2008). All solid-state battery with sulfur electrode and thio-LISICON electrolyte. J. Power Sources 182, 621-625. doi: 10.1016/j.jpowsour.2008.03.030

Kokal, I., Ramanujachary, K. V., Notten, P. H. L., and Hintzen, H. T. (2012). Sol-gel synthesis and lithium ion conduction properties of garnet-type $\mathrm{Li}_{6} \mathrm{BaLa}_{2} \mathrm{Ta}_{2} \mathrm{O}_{12}$. Mater. Res. Bull. 47, 1932-1935. doi: 10.1016/j.materresbull.2012.04.032

Lai, C. H., Lu, M. Y., and Chen, L. J. (2011). Metal sulfide nanostructures: synthesis, properties and applications in energy conversion and storage. J. Mater. Chem. 22, 19-10. doi: 10.1039/C1JM13879K

Lee, C. H., Joo, K. H., Kim, J. H., Woo, S. G., Sohn, H. J., Kang, T., et al. (2002). Characterizations of a new lithium ion conducting $\mathrm{Li}_{2} \mathrm{O}-\mathrm{SeO}_{2}-\mathrm{B}_{2} \mathrm{O}_{3}$ glass electrolyte. Solid State Ionics 149, 59-65. doi: 10.1016/S0167-2738(02)00137-6

Lee, F., Tsai, M.-C., Lin, M.-H., Ni'mah, Y. L., Hy, S., Kuo, C.-Y., et al. (2017). Capacity retention of lithium sulfur batteries enhanced with nanosized TiO2-embedded polyethylene oxide. J. Mater. Chem. A 5, 6708-6715. doi: 10.1039/C6TA10755A

Li, L., Pascal, T. A., Connell, J. G., Fan, F. Y., Meckler, S. M., Ma, L., et al. (2017). Molecular understanding of polyelectrolyte binders that actively regulate ion transport in sulfur cathodes. Nat. Commun. 8:2277. doi: 10.1038/s41467-017-02410-6

Li, W., Zhang, Q., Zheng, G., Seh, Z. W., Yao, H., and Cui, Y. (2013). Understanding the role of different conductive polymers in improving the nanostructured sulfur cathode performance. Nano Lett. 13, 5534-5540. doi: $10.1021 / \mathrm{nl} 403130 \mathrm{~h}$

Li, Y., Han, J. T., Wang, C. A., Xie, H., and Goodenough, J. B. (2012). Optimizing $\mathrm{Li}+$ conductivity in a garnet framework. J. Mater. Chem. 22, 15357-15361. doi: $10.1039 / \mathrm{c} 2 \mathrm{jm} 31413 \mathrm{~d}$

Li, Y., Xu, B., Xu, H., Duan, H., Lü, X., Xin, S., et al. (2017). Hybrid polymer/garnet electrolyte with a small interfacial resistance for lithium-ion batteries. Angewandte Chem. Int. Edn. 56, 753-756. doi: 10.1002/anie.201608924

Li, Z., Wu, H. B., and Lou, X. W. (2016). Rational designs and engineering of hollow micro-/nanostructures as sulfur hosts for advanced lithium-sulfur batteries. Energy Environ. Sci. 9, 3061-3070. doi: 10.1039/C6EE02364A

Liang, C. C. (1973). Conduction characteristics of the lithium iodide-aluminum oxide solid electrolytes. J. Electrochem. Soc. 120:1289. doi: 10.1149/1.2403248

Liang, X., Wen, Z., Liu, Y., Wu, M., Jin, J., Zhang, H., et al. (2011a). Improved cycling performances of lithium sulfur batteries with LiNO3-modified electrolyte. J. Power Sources 196, 9839-9843. doi: 10.1016/j.jpowsour.2011.08.027

Liang, X., Wen, Z., Liu, Y., Zhang, H., Huang, L., and Jin, J. (2011b). Highly dispersed sulfur in ordered mesoporous carbon sphere as a composite cathode for rechargeable polymer Li/S battery. J. Power Sources 196, 3655-3658. doi: 10.1016/j.jpowsour.2010.12.052

Lin, Y., Wang, X., Liu, J., and Miller, J. D. (2017). Natural halloysite nano-clay electrolyte for advanced all-solid-state lithium-sulfur batteries. Nano Energy 31, 478-485. doi: 10.1016/j.nanoen.2016.11.045

Lin, Z., Liu, Z., Dudney, N. J., and Liang, C. (2013a). Lithium superionic sulfide cathode for all-solid lithium-sulfur batteries. Acs Nano 7, 2829-2833. doi: 10.1021/nn400391h

Lin, Z., Liu, Z., Fu, W., Dudney, N. J., Liang, C. (2013b). Lithium polysulfidophosphates: a family of lithium-conducting sulfur-rich compounds for lithium-sulfur batteries and angewandte chemie-international edition. Angew Chem Int Ed Engl. 52, 7460-7463. doi: 10.1002/anie.201300680

Liu, M., Zhou, D., He, Y.-B., Fu, Y., Qin, X., Miao, C., et al. (2016). Novel gel polymer electrolyte for high-performance lithium-sulfur batteries. Nano Energy 22, 278-289. doi: 10.1016/j.nanoen.2016.02.008

Long, P., Xu, Q., Peng, G., Yao, X., and Xu, X. (2016). NiS nanorods as cathode materials for all-solid-state lithium batteries with excellent rate capability and cycling stability. Chemelectrochem 3, 764-769. doi: 10.1002/celc.201500570

Luo, W., Gong, Y., Zhu, Y., Li, Y., Yao, Y., Zhang, Y., et al. (2017). Reducing interfacial resistance between garnet-structured solid-state electrolyte and Li-metal anode by a germanium layer. Adv. Mater. 29:22. doi: $10.1002 /$ adma.201606042
Ma, L., Zhuang, H., Lu, Y., Moganty, S. S., Hennig, R. G., and Archer, L. A. (2014). Tethered molecular sorbents: enabling metal-sulfur battery cathodes. Adv. Energy Mater. 4:1400390. doi: 10.1002/aenm.201400390

Machida, N., Kobayashi, K., Nishikawa, Y., and Shigematsu, T. (2004). Electrochemical properties of sulfur as cathode materials in a solid-state lithium battery with inorganic solid electrolytes. Solid State Ionics Diffus. React. 175, 247-250. doi: 10.1016/j.ssi.2003.11.033

Machida, N., and Shigematsu, T. (2004). An all-solid-state lithium battery with sulfur as positive electrode materials. Chem. Lett. 33, 376-377. doi: $10.1246 / \mathrm{cl} .2004 .376$

Maier, J. (1995). Ionic conduction in space charge regions. Progress Solid State Chem. 23, 171-263. doi: 10.1016/0079-6786(95)00004-E

Manthiram, A., Yu, X., and Wang, S. (2017). Lithium battery chemistries enabled by solid-state electrolytes. Nature Reviews Materials, 2, 16103. doi: 10.1038/natrevmats.2016.103

Matsuyama, T., Sakuda, A., Hayashi, A., Togawa, Y., Mori, S., and Tatsumisago, M. (2013). Electrochemical properties of all-solid-state lithium batteries with amorphous titanium sulfide electrodes prepared by mechanical milling. J. Solid State Electrochem. 17, 2697-2701. doi: 10.1007/s10008-013-2157-5

Mikhaylik, Y. V., and Akridge, J. R. (2004). Polysulfide shuttle study in the Li/S battery system. J. Electrochem. Soc. 151, A1969-A1976. doi: 10.1149/1.1806394

Nagao, M., Hayashi, A., and Tatsumisago, M. (2012). Fabrication of favorable interface between sulfide solid electrolyte and $\mathrm{Li}$ metal electrode for bulk-type solid-state Li/S battery. Electrochem. Commun. 22, 177-180. doi: 10.1016/j.elecom.2012.06.015

Nagao, M., Imade, Y., Narisawa, H., Kobayashi, T., Watanabe, R., Yokoi, T., et al. (2013a). All-solid-state Li-sulfur batteries with mesoporous electrode and thio-LISICON solid electrolyte. J. Power Sources 222, 237-242. doi: 10.1016/j.jpowsour.2012.08.041

Nagao, M., Imade, Y., Narisawa, H., Watanabe, R., Yokoi, T., Tatsumi, T., et al. (2013b). Reaction mechanism of all-solid-state lithium-sulfur battery with two-dimensional mesoporous carbon electrodes. J. Power Sources 243, 60-64. doi: 10.1016/j.jpowsour.2013.05.037

Nagao, M., Suzuki, K., Imade, Y., Tateishi, M., Watanabe, R., Yokoi, T., et al. (2016). All-solid-state lithium-sulfur batteries with threedimensional mesoporous electrode structures. J. Power Sources 330, 120-126. doi: 10.1016/j.jpowsour.2016.09.009

Nagata, H., and Chikusa, Y. (2014a). A lithium sulfur battery with high power density. J. Power Sources 264, 206-210. doi: 10.1016/j.jpowsour.2014.04.106

Nagata, H., and Chikusa, Y. (2014b). Transformation of P2S5 into a solid electrolyte with ionic conductivity at the positive composite electrode of all-solid-state lithium-sulfur batteries. Energy Techn. 2, 753-756. doi: 10.1002/ente. 201402040

Nagata, H., and Chikusa, Y. (2014c). Activation of sulfur active material in an all-solid-state lithium-sulfur battery. J. Power Sources 263, 141-144. doi: 10.1016/j.jpowsour.2014.04.032

Nagata, H., and Chikusa, Y. (2016). An all-solid-state lithium-sulfur battery using two solid electrolytes having different functions. J. Power Sources 329, 268-272. doi: 10.1016/j.jpowsour.2016.08.058

Nair, J. R., Bella, F., Angulakshmi, N., Stephan, A. M., and Gerbaldi, C. (2016) Nanocellulose-laden composite polymer electrolytes for high performing lithium-sulphur batteries. Energy Storage Mater. 3:S2405829715300945. doi: 10.1016/j.ensm.2016.01.008

Pang, Q., Liang, X., Kwok, C. Y., and Nazar, L. F. (2016). Advances in lithiumsulfur batteries based on multifunctional cathodes and electrolytes. Nat. Energy 1:16132. doi: 10.1038/nenergy.2016.132

Park, K., Cho, J. H., Jang, J.-H., Yu, B.-C., De La Hoz, A. T., Miller, K. M., et al. (2015). Trapping lithium polysulfides of a Li-S battery by forming lithium bonds in a polymer matrix. Energy Environ. Sci. 8, 2389-2395. doi: 10.1039/C5EE01809A

Peng, H. P., Huang, J. Q., Cheng, X. B., and Zhang, Q. (2017). Review on high-loading and high-energy lithium-sulfur batteries. Adv. Energy Mater. 7:1700260. doi: 10.1002/aenm.2017 00260

Rao, M., Geng, X., Li, X., Hu, S., and Li, W. (2012). Lithium-sulfur cell with combining carbon nanofibers-sulfur cathode and gel polymer electrolyte. J. Power Sources 212, 179-185. doi: 10.1016/j.jpowsour.2012. 03.111 
Rao, R., li, X., Liao, Y., and Li, X. (2015). Preparation and performance of a composite polyimide/poly(vinylidene fluoride-co-hexafluoropropylene)/nanoAl2O3polymer electrolyte for lithium-sulfur cell. Ionics 21, 1937-1943. doi: 10.1007/s11581-014-1360-4

Rosenman, A., Markevich, E., Salitra, G., Aurbach, D., Garsuch, A., and Chesneau, F. F. (2015). Review on li-sulfur battery systems: an integral perspective. $A d v$. Energy Mater. 5:1500212. doi: 10.1002/aenm.201500212

Ryoo, H. J., Kim, H. T., Lee, Y. G., Park, J. K., and Moon, S. I. (1998). Thermal and electrochemical characteristics of plasticized polymer electrolytes based on poly(acrylonitrile-co-methyl methacrylate). J. Solid State Electrochem. 3, 1-6. doi: 10.1007/s100080050123

Sakuda, A., Hayashi, A., and Tatsumisago, M. (2010). Interfacial observation between LiCoO2 electrode and Li2S-P2S5 solid electrolytes of all-solid-state lithium secondary batteries using transmission electron microscopy. Chem. Mater. 22, 949-956. doi: 10.1021/cm901819c

Schneider, H., Thomas Wei, B, Scordilis-Kelley, C., Maeyer, J., Leitner, K., Peng, H. J., et al. (2017). Electrolyte decomposition and gas evolution in a lithium-sulfur cell upon long-term cycling. Electrochim. Acta 243, 26-32. doi: 10.1016/j.electacta.2017.05.034

Scrosati, B., Croce, F., and Panero, S. (2001). Progress in lithium polymer battery R\&D. J. Power Sources 100, 93-100. doi: 10.1016/S0378-7753(01)00886-2

Seh, Z. W., Zhang, Q., Li, W., Zheng, G., Yao, H., and Cui, Y. (2013). Stable cycling of lithium sulfide cathodes through strong affinity with a bifunctional binder. Chem. Sci. 4:3673. doi: 10.1039/c3sc51476e

Sheng, O., Jin, C., Luo, J., Yuan, H., Fang, C., Huang, H., et al. (2017). Ionic conductivity promotion of polymer electrolyte with ionic liquid grafted oxides for all-solid-state lithium-sulfur batteries. J. Mater. Chem. A 5, 12934-12942. doi: 10.1039/C7TA03699J

Shin, J. H., and Cairns, E. J. (2008). N-Methyl-(n-butyl)pyrrolidinium bis(trifluoromethanesulfonyl)imide-LiTFSI-poly(ethylene glycol) dimethyl ether mixture as a Li/S cell electrolyte. J. Power Sources 177, 537-545. doi: 10.1016/j.jpowsour.2007.11.043

Shin, J. H., Jung, S. S., Kim, K. W., Ahn, H. J., and Ahn, J. H. (2002a). Preparation and characterization of plasticized polymer electrolytes based on the PVdFHFP copolymer for lithium/sulfur battery. J. Mater. Sci. Mater. Electron. 13, 727-733. doi: 10.1023/A:1021521207247

Shin, J. H., Kim, K. W., Ahn, H. J., and Ahn, J. H. (2002b). Electrochemical properties and interfacial stability of (PEO)(10)LiCF3SO3TinO2n-1 composite polymer electrolytes for lithium/sulfur battery. Mater. Sci. Eng. B Solid State Mater. Adv. Techn. 95, 148-156. doi: 10.1016/S0921-5107(02)00226-X

Song, M. K., Zhang, Y., and Cairns, E. J. (2013). A long-life, high-rate lithium/sulfur cell: a multifaceted approach to enhancing cell performance. Nano Lett. 13, 5891-5899. doi: 10.1021/nl402793z

Tao, X., Liu, Y., Liu, W., Zhou, G., Zhao, J., Lin, D., et al. (2017). Solid-state lithium-sulfur batteries operated at $37^{\circ} \mathrm{c}$ with composites of nanostructured Li7La3Zr2O12/Carbon foam and polymer. Nano Lett. 17, 2967-2972. doi: 10.1021/acs.nanolett.7b00221

Tatsumisago, M. (2004). Glassy materials based on Li2S for all-solid-state lithium secondary batteries. Solid State Ionics 175, 13-18. doi: 10.1016/j.ssi.2004.09.012

Tomonari, T., Hiroyuk, K., Nakanishib, K., Tabuchi, M., Sakaebe, H., Ohta, T., et al. (2010). All-Solid-State Lithium Secondary Battery with Li2S - C composite positive electrode prepared by spark-plasma-sintering process. J. Electrochem. Soc. 157, A1196-A1201. doi: 10.1149/1.3486083

Verma, M. L., Minakshi, M., and Singh, N. K. (2014a). Structural and electrochemical properties of nanocomposite polymer electrolyte for electrochemical devices. Indust. Eng. Chem. Res. 53, 14993-15001. doi: $10.1021 /$ ie $502615 \mathrm{w}$

Verma, M. L., Minakshi, M., and Singh, N. K. (2014b). Synthesis and characterization of solid polymer electrolyte based on activated carbon for solid state capacitor. Electrochim. Acta 137, 497-503. doi: 10.1016/j.electacta.2014.06.039

Wang, C., Gong, Y., Liu, B., Fu, K., Yao, Y., Hitz, E., et al. (2017). Conformal, nanoscale ZnOSurface modification of garnet-based solidstate electrolyte for lithium metal anodes. Nano Lett. 17, 565-571. doi: 10.1021/acs.nanolett.6b04695
Wang, Q., Guo, J., Wu, T., Jin, J., Yang, J., Wen, Z., et al. (2017). Improved performance of Li-S battery with hybrid electrolyte by interface modification. Solid State Ionics 300, 67-72. doi: 10.1016/j.ssi.2016.11.001

Wang, Q., Jin, J., Wu, X., Ma, G., Yang, J., and Wen, Z. (2014). A shuttle effect free lithium sulfur battery based on a hybrid electrolyte. Phys. Chem. Chem. Phys. 16, 21225-21229. doi: 10.1039/C4CP03694H

Wang, Q., Wen, Z., Jin, J., Guo, J., Huang, X., Yang, J., et al. (2016). A gel-ceramic multi-layer electrolyte for long-life lithium sulfur batteries. Chem. Commun. 52, 1637-1640. doi: 10.1039/C5CC08279J

Wang, S., Ding, Y., Zhou, G., Yu, G., and Manthiram, A. (2016). Durability of the $\mathrm{Li}_{1+x} \mathrm{Ti}_{2-x} \mathrm{Al}_{x}\left(\mathrm{PO}_{4}\right)_{3}$ solid electrolyte in lithium sulfur batteries. Acs Energy Lett. 1, 1080-1085. doi: 10.1021/acsenergylett.6b00481

Wang, X., Hou, Y., Zhu, Y., Wu, Y., and Holze, R. (2013). An aqueous rechargeable lithium battery using coated li metal as anode. Sci. Rep. 3:1401. doi: 10.1038/srep01401

Wang, Z., Huang, B., Huang, H., Chen, L., Xue, R., and Wang, F. (1996). Investigation of the position of $\mathrm{Li}+$ ions in a polyacrylonitrile-based electrolyte by Raman and infrared spectroscopy. Electrochim. Acta 41, 1443-1446. doi: 10.1016/0013-4686(95)00392-4

Wen, C. J., and Huggins, R. A. (1980). Thermodynamic and mass transport properties of "LiIn". Mater. Res. Bull. 15, 1225-1234. doi: 10.1016/0025-5408(80)90024-0

Wu, F., Lee, J. T., Nitta, N., Kim, H., Borodin, O., and Yushin, G. (2015). Lithium iodide as a promising electrolyte additive for lithium-sulfur batteries: mechanisms of performance enhancement. Adv. Mater. 27, 101-108. doi: 10.1002/adma.201404194

Wu, F., Qian, J., Chen, R., Lu, J., Li, L., Wu, H., et al. (2014). An effective approach to protect lithium anode and improve cycle performance for $\mathrm{Li}$ S batteries. ACS Appl. Mater. Interfaces 6:140822155118003. doi: 10.1021/am $504345 \mathrm{~s}$

Wu, Y., Wang, Y., Feng, J., Ma, Z., and Shao, G. (2016). High capacity and cycle stability Rechargeable Lithium-Sulfur batteries by sandwiched gel polymer electrolyte. Electrochim. Acta 210, 71-78. doi: 10.1016/j.electacta.2016. 05.087

Xia, Y., Wang, X., Xia, X., Xu, R., Zhang, S., Wu, J., et al. (2017). A newly designed composite gel polymer electrolyte based on poly(vinylidene fluoridehexafluoropropylene) (PVDF-HFP) for enhanced solid-state lithium-sulfur batteries. Chemistry 23:60. doi: 10.1002/chem.201703464

$\mathrm{Xu}, \quad$ K. (2004). Nonaqueous liquid electrolytes for lithium-based rechargeable batteries. Chem. Rev. 104, 4303-4417. doi: 10.1021/cr0 $30203 \mathrm{~g}$

$\mathrm{Xu}, \mathrm{R}, \mathrm{Lu}, \mathrm{J}$. , and Amine, K. (2015). Progress in mechanistic understanding and characterization techniques of li-s batteries. Adv. Energy Mater. 5:1500408. doi: 10.1002/aenm.201500408

Xu, R. C., Xia, X. H., Wang, X. L., Xiaa, Y., and Tu, J. P. (2017). Tailored Li2S-P2S5 glass-ceramic electrolyte by MoS2 doping, possessing high ionic conductivity for all-solid-state lithium-sulfur batteries. J. Mater. Chem. A. 5, 2829-2834. doi: 10.1039/C6TA10142A

$\mathrm{Xu}, \mathrm{X}$. X., and Wen, Z. Y. (2005). Glass and glass-ceramics solid electrolytes for lithium-ion battery. J. Inorganic Mater. 20, 21-26.

Yao, X., Liu, D., Wang, C., Long, P., Peng, G., Hu, Y. S., et al. (2016). Highenergy all-solid-state lithium batteries with ultralong cycle life. Nano Lett. 16, 7148-7154. doi: 10.1021/acs.nanolett.6b03448

Ye, Y., Wu, F., Xu, S., Qu, W., Li, L., and Chen, R. (2018). Designing realizable and scalable techniques for practical lithium sulfur batteries: a perspective. J. Phys. Chem. Lett. 9, 1398-1414. doi: 10.1021/acs.jpclett.7b03165

Yu, X., Bi, Z., Zhao, F., and Manthiram, A. (2016). Polysulfide-Shuttle control in Lithium-Sulfur batteries with a chemically/electrochemically compatible NaSICON-Type solid electrolyte. Adv. Energy Mater. 6:24. doi: 10.1002/aenm.201601392

Yu, X. G., Xie, J. Y., Yang, J., and Wang, K. (2004). All solid-state rechargeable lithium cells based on nano-sulfur composite cathodes. J. Power Sources 132, 181-186. doi: 10.1016/j.jpowsour.2004.01.034

Zeng, S.-L., Wang, H.-X., and Dong, C. (2014). Synthesis and electrical conductivity of nanocrystalline tetragonal FeS. Chinese Phys. B 23:8. doi: 10.1088/1674-1056/23/8/087203 
Zhang, C., Lin, Y., and Liu, J. (2015). Sulfur double locked by a macro-structural cathode and a solid polymer electrolyte for lithium-sulfur batteries. J. Mater. Chem. A 3, 10760-10766. doi: 10.1039/C5TA01037C

Zhang, S., Ueno, K., Dokko, K., and Watanabe, M. (2015). Recent advances in electrolytes for lithium-sulfur batteries. Adv. Energy Mater. 5:1500117. doi: 10.1002/aenm.201500117

Zhang, S. S. (2013). Liquid electrolyte lithium/sulfur battery: Fundamental chemistry, problems, and solutions. J. Power Sources 231, 153-162. doi: 10.1016/j.jpowsour.2012.12.102

Zhang, S. S., and Tran, D. T. (2013). How a gel polymer electrolyte affects performance of lithium/sulfur batteries. Electrochim. Acta 114, 296-302. doi: 10.1016/j.electacta.2013.10.069

Zhang, X., Wang, W., Wang, A., Huang, Y., Yuan, K., Yu, Z., et al. (2014). Improved cycle stability and high security of Li-B alloy anode for lithium-sulfur battery. J. Mater. Chem. A 2, 11660-11665. doi: 10.1039/C4TA01709A

Zhang, Y., Chen, K., Shen, Y., Lin, Y., and Nan, C.-W. (2017). Synergistic effect of processing and composition $\mathrm{x}$ on conductivity of $\mathrm{xLi}_{2} \mathrm{~S}-(100-$ x) $\mathrm{P}_{2} \mathrm{~S}_{5}$ electrolytes. Solid State Ionics 305, 1-6. doi: 10.1016/j.ssi.2017. 03.024

Zhang, Y., Zhao, Y., Bakenov, Z., Babaa, M.-R., Konarov, A., Ding, C., et al. (2013). Effect of graphene on sulfur/polyacrylonitrile nanocomposite cathode in high performance lithium/sulfur batteries. J. Electrochem. Soc. 160, A1194-A1198. doi: 10.1149/2.068308jes

Zhang, Y., Zhao, Y., Bakenov, Z., and Chen, P. (2014). Poly(vinylidene fluorideco-hexafluoropropylene)/poly(methylmethacrylate)/nanoclay composite gel polymer electrolyte for lithium/sulfur batteries. J. Solid State Electrochem. 18, 1111-1116. doi: 10.1007/s10008-013-2366-y

Zhang, Y., Zhao, Y., Gosselink, D., and Chen, P. (2015). Synthesis of poly(ethyleneoxide)/nanoclay solid polymer electrolyte for all solid-state lithium/sulfur battery. Ionics 21, 381-385. doi: 10.1007/s11581-014-1176-2

Zhang, Z., Lai, Y., Zhang, Z., Zhang, K., and Li, J. (2014). Al2O3-coated porous separator for enhanced electrochemical performance of lithium sulfur batteries. Electrochim. Acta 129, 55-61. doi: 10.1016/j.electacta.2014.02.077
Zhao, Y., Wu, C., Peng, G., Chen, X., Yao, X., Bai, Y., et al. (2016). A new solid polymer electrolyte incorporating Li10GeP2S12 into a polyethylene oxide matrix for all-solid-state lithium batteries. J. Power Sources 301, 47-53. doi: 10.1016/j.jpowsour.2015.09.111

Zhao, Y., Zhang, Y., and Bakenov, Z. (2013). Electrochemical performance of lithium gel polymer battery with nanostructured sulfur/carbon composite cathode. Solid State Ionics 234, 40-45. doi: 10.1016/j.ssi.2013.01.002

Zhou, D., Liu, R., He, Y. B., Li, F., Li, B., Yang, Q. H., et al. (2016). $\mathrm{SiO}_{2}$ hollow nanosphere-based composite solid electrolyte for lithium metal batteries to suppress lithium dendrite growth and enhance cycle life. Adv. Energy Mater. 6:7. doi: 10.1002/aenm.201502214

Zhu, K., Liu, Y., and Liu, J. (2014). A fast charging/discharging all-solid-state lithium ion battery based on PEO-MIL-53(Al)-LiTFSI thin film electrolyte. RSC Adv. 4, 42278-42284. doi: 10.1039/C4RA06208F

Zhu, S., Ma, F., Wang, Y., Yan, W., Sun, D., and Jin, Y. (2017). New small molecule gel electrolyte with high ionic conductivity for Li-S batteries. J. Mater. Sci. 52, 4086-4095. doi: 10.1007/s10853-016-0671-4

Zhu, X. J., Wen, Z. Y., Gu, Z. H., and Lin, Z. X. (2005). Electrochemical characterization and performance improvement of lithium/sulfur polymer batteries. J. Power Sources 139, 269-273. doi: 10.1016/j.jpowsour.2004.07.002

Conflict of Interest: The authors declare that the research was conducted in the absence of any commercial or financial relationships that could be construed as a potential conflict of interest.

Copyright (C) 2019 Wang, Cao, Liu and Sun. This is an open-access article distributed under the terms of the Creative Commons Attribution License (CC BY). The use, distribution or reproduction in other forums is permitted, provided the original author(s) and the copyright owner(s) are credited and that the original publication in this journal is cited, in accordance with accepted academic practice. No use, distribution or reproduction is permitted which does not comply with these terms. 